\title{
Debris-carrying behaviour of bark lice immatures preserved in 100 million years old amber
}

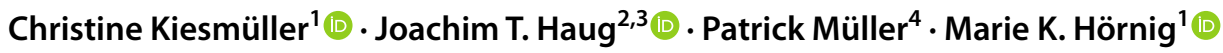

Received: 2 October 2020 / Accepted: 10 May 2021 / Published online: 29 July 2021

(c) The Author(s) 2021

\begin{abstract}
Camouflage strategies, including several types of concealments, are known for several insect groups today, such as immatures of some species within reduviid bugs (Hemiptera), lace wings (Neuroptera), caddisflies (Trichoptera) and bark lice (Psocodea). However, camouflage has only rarely been reported in the fossil record. Here we report findings of four bark lice preserved in 100 Million year old amber from Myanmar, which represent the first fossil evidence for masking behaviour in Cretaceous representatives of Psocodea. All four of these, probably not conspecific, and immature bark lice carry sand granules and organic material atop their back, which probably resulted in camouflaging them against the background (e.g. bark) to avoid detection by predators. We briefly summarise concepts of camouflage and examples of decoration behaviour within insects, as well as possible "receiver" (i.e. predators) of the camouflage of the herein described bark lice. The exact phylogenetic position of the specimens remains unclear, due to the scarce fossil record of Cretaceous immatures of Psocodea, as well as extant immatures. This demonstrates the importance of findings as reported here, as a wide knowledge of morphology and development of a certain group is crucial to get an insight into their evolution and reconstructing environments in deep time.
\end{abstract}

Keywords Psocodea $\cdot$ Myanmar amber $\cdot$ Camouflage $\cdot$ Debris carrying $\cdot$ Prey adaptation

\section{Introduction}

Camouflage, in the general sense, is used by animals to hamper their detection or recognition, e.g. to avoid being spotted by predators, or prey. There are overall three entities involved that interact specifically with each other: the primary signal generator (i.e. the mimicked species or

Handling Editor: Mike Reich.

Christine Kiesmüller

christine.kiesmueller@palaeo-evo-devo.info

1 Cytology and Evolutionary Biology, Universität Greifswald, Zoologisches Institut und Museum, Soldmannstr. 23, 17489 Greifswald, Germany

2 Biologie II, Ludwig-Maximilians-Universität München, Biocenter, Großhaderner Str. 2, 82152 Planegg-Martinsried, Germany

3 GeoBio-Center der Ludwig-Maximilians-Universität München, Richard-Wagner-Str. 10, 80333 Munich, Germany

4 Kreuzbergstr. 90, 66482 Zweibrücken, Germany background), the secondary signal generator (i.e. the mimic species) and the signal receiver (i.e. deceived species).

\section{The concept of camouflage and terminology}

The terminology of camouflage strategies and types of concealments have been controversially discussed (Poulton 1898; Cott 1940; Wickler 1968; Wiens 1978; Vane-Wright 1980 and comments on it in Cloudsley-Thompson 1981; Edmunds 1981 and Rothschild 1981; Robinson 1981) and underlying concepts of these have been varied and not universally agreed upon (Rettenmeyer 1970; Roesler and Küppers 1977; Endler 1981; Roesler 1987; Stevens and Merilaita 2009). Several terms, such as 'crypsis', 'masquerade', 'aggressive mimicry' and others have been either used as different categories or as part of, or even partly synonymously. These various concepts are based on different criteria of distinctions, such as appearance (for visual camouflage e.g. pattern classes, Hanlon 2007), or whether a background or another species is mimicked, or the intention (e.g. aggressive, defensive etc.) (Endler 1981). 
Endler (1981) summarized several concepts of mimicryassociated phenomena and categorized them based on nonmutually exclusive levels of perspective. The first level differentiates on whether or not the signal receiver has to distinguish between the background and the mimic or between another species and the mimic. The second level discriminates on whether the similarities between the mimic and the mimicked species have an effect (i.e. population dynamics or evolution) on the mimicked species or not. In brief, if the mimic imitates a background, Endler (1981) classifies this as crypsis (here synonymous to camouflage; for more detailed information and exceptions see Endler 1981). In contrast, the term mimicry means that the mimic imitates a specific object or species, further specified in masquerade (e.g. plant-part or dung and stone mimicry), or if this imitation affects the population dynamics or evolution of one or several mimicked species in i.a. Batesian mimicry (mimic of a dangerous/inedible species by harmless species) or Müllerian mimicry (mimic of a dangerous/inedible species by another dangerous/inedible species) and Mertensian mimicry (mimic of a harmless species by a dangerous species) (Endler 1981 and references therein).

In contrast to the latter classification, Stevens and Merilaita (2009) suggest to discriminate different camouflage types (here used as umbrella term) based on the function instead of the appearances, to describe "what the adaptation may do (e.g. breaking up form, distracting attention)". In their concept, crypsis and masquerade can be distinguished based on whether these strategies prevent detection (crypsis) or recognition (masquerade). Here, the term crypsis means that an individual cannot be detected as anything but a background for the deceived species. In the case of masquerade, the 'masked' individual can be detected, but not recognized as 'interesting' for the deceived species (remark: so maybe 'misrecognition' would be a more proper term here).

Camouflage (sensu Stevens and Merilaita 2009) strategies have been mostly studied within visual camouflage, and therein mostly camouflage strategies related to colour patterns (e.g. Endler 1978, 1981; Cuthill and Troscianko 2009). There are primarily two strategies which are widespread within Metazoa: background matching and disruptive colouration (both part of crypsis in Stevens and Merilaita 2009). Background matching employs colour patterns to become inconspicuous against the animals usual background to avoid detection and/or recognition by the signal receiver. In specific cases the animals colouration can be actively changing, like exhibited by most famously the chameleon (e.g. Cuadrado et al. 2001; Stuart-Fox et al. 2006) or many types of squids and octobrachians (e.g. Meijer-Kuiper 1993; Hanlon 2007). Disruptive colouration is a strategy to mask a body outline by usage of a distinct set of markings that creates false boundaries to avoid recognition by the signal receiver.
Other visual camouflage strategies, which are not based on colour patterns, are motion camouflage, masquerade and decorating/masking. Motion camouflage, as for example used by some dragonflies, is used to actively disguise the dragonfly while in flight to appear stationary for the signal receiver (e.g. Mitzutani et al. 2003). Masquerade is another concealment strategy; species exhibiting this behaviour resemble mostly inanimate or inedible objects like bird droppings or twigs to avoid recognition by the signal receiver (e.g. Skelhorn et al. 2010) (though it has to be mentioned, that there was discussion whether masquerade is a camouflaging strategy or mimicry; Endler 1981). Decorating, masking or also debris carrying is a strategy where animals carry miscellaneous debris to blend into their environment; though this strategy is not only a visual strategy, as some debris-carrying animals use the debris to also camouflage themselves olfactorily (e.g. Brandt and Mahsberg 2002; Ramírez et al. 2013; Ruxton and Stevens 2015 for reduviid bugs or Aldrich and Zhang 2016 and references therein for neuropteran larvae).

There are also many non-visual camouflage strategies (Ruxton 2009) in almost all sensory modalities. Olfactory or chemical camouflage seems to be among the better studied non-visual camouflage strategy (e.g. Howard et al. 1990; Dettner and Liepert 1994). Other examples of non-visual camouflage include acoustical avoidance, electric 'signal cloaking', wake following, vibration and heat, though the last three seem to be either rare or not investigated in detail (compare Ruxton 2009 and references therein).

\section{The fossil record of camouflage}

Camouflage in the fossil record has been sparsely reported on (but see Kácha and Petr 1995 for review and other examples in e.g. Pérez-de la Fuente et al. 2012; Wang et al. 2016). This seems partly surprising, considering the widespread nature of camouflage strategies employed by animals today. Though considering that the camouflage strategies most studied involve colour patterns as discussed above which is rarely preserved in fossils, this is probably not as surprising. Also non-visual camouflage strategies are also not, or only indirectly observable in the fossil record. Regardless of these difficulties it is also impossible to corroborate cases of camouflage in the fossil record as the effect of such morphological or behavioural adaptations cannot be tested. Surprisingly this also seems to be a problem with camouflage in extant animals, as the camouflage is described, but for only a few examples experimental data exists to provide clear indications of the actual camouflage effect on the intended organism (compare e.g. Brandt and Mahsberg 2002 and references therein). 


\section{Bark lice}

Psocodea is an in-group of Insecta with about 10,000 formally described extant species (Yoshizawa 2005; compare also Smithers 1972; Yoshizawa 2002 and Baz 2008 with Grimaldi and Engel 2006a, b). More precisely it is an ingroup of Paraneoptera, sister group to the lineage Condylognatha, including Thysanoptera (thrips) and Hemiptera (including various forms such as true bugs, tree hoppers and scale insects). Psocodea has in the past been differentiated into two groups: Psocoptera (the group of bark and book lice) and Phthiraptera (the group of true lice, possibly not monophyletic, see discussion); yet numerous studies have shown that Phthiraptera is an in-group of Psocoptera (e.g. Kim and Ludwig 1978; Lyal 1985; Ax 2000; Grimaldi and Engel 2005) making Psocoptera a synonym to Psocodea. That also means that true lice (representatives of Phthiraptera) are in fact highly derived book lice (similar to the fact that birds are dinosaurs). More recent studies additionally question the monophyly of Phthiraptera (Johnson et al. 2004).

Bark and book lice are usually small representatives of Insecta with a size range from less than one millimetre up to about two and a half centimetres (Baz 2008). Due to the small size, and also because they do not seem to hold much medical or agricultural significance (Grimaldi and Engel 2005, but see e.g. Kučerová 1997, 1998 for pest species within the bark and book lice) they are understudied. Bark and book lice inhabit mostly woody areas, where they can be found on trees (bark or foliage), shrubbery or on/in the soil. Some species (book lice) have also been found in bird nests (Hicks 1959 and references therein) or human dwellings, as there are a few pest species known in storage buildings (Enderlein 1924; Turner 1994; Kučerová 1998, 2002; Kučerová et al. 2009; Ahmedani et al. 2010; Athanassiou et al. 2010; Yang et al. 2013). Many bark-dwelling bark lice (hence the name!) show some sort of camouflage strategy, mostly certain colour patterns on their wings that make them inconspicuous against their background (e.g. New 1987), which adds to the list of reasons why they are not as well studied as other in-groups of Insecta (Grimaldi and Engel 2005).

Psocodean-type insects have been supposed to exist since the Carboniferous (Nel et al. 2013), with multiple findings throughout the (subsequent) Permian (e.g. Tillyard 1926; Carpenter 1932, 1933, 1939; Knight 1950; see further also Smithers 1972), though definite psocodeans have only been identified with little doubt from the Cretaceous, and there mostly within amber (Mockford et al. 2013 for overview; French: Schlüter 1978 (Bezonnais, Val-d'Oise); Perrichot et al. 2003 (Archingeay, Charente-Maritime); Perrichot 2004 (Archingeay, Charente-Maritime); Perrichot et al. 2007 (overview French ambers); Azar et al. 2009
(Archingeay, Charente-Maritime); Azar et al. 2015 (Vendée amber); Lebanese (Jezzine/Hammana): Azar 2000; Poinar and Milki 2001; Perrichot et al. 2003; Azar and Nel 2004; Grimaldi and Engel 2006b; Azar et al. 2008; Azar et al. 2010a, b; Choufani et al. 2011; Azar and Nel 2011; Myanmar (Hukawng Valley, Kachin State): see further Ross 2020; Siberian (Taymyr Peninsula): Vishnyakova 1975; Azar and Engel 2008; Canada (Alberta/Minetoba): Spahr 1992; Grimaldi and Engel 2006b; Spanish (Basque-Cantabrian Basin, Álava): Baz and Ortuño 2000, 2001a, b; USA (Sayreville, New Jersey): Gelhaus and Johnson 1996; Azar et al. 2010a, b). In Myanmar amber (also known as "Burmese" amber or Burmite) there are 22 known species of Psocodea so far (Ross 2020; Yoshizawa and Lienhard 2020).

There is sparse report of a bark lice fossil that exhibits any type of camouflage; there is only one mentioned in an embedded clause in Boucot and Poinar (2010: 189, fig. 254) where the depicted bark louse in Dominican amber is carrying a dense amount of debris atop their back (whether the individual is immature or adult is not mentioned). This sparseness may be attributed to that the majority of bark lice fossils that have been described have been adult and winged, where the camouflage strategy used is mostly colour pattern based, which as described above, is rarely preserved and/ or discussed. Other camouflage strategies as exhibited by extant species of bark lice include cuticular protrusions on mostly the thorax of wingless bark-dwelling bark lice that resemble plant-parts or debris-carrying within immature stages of certain bark lice species as a concealment strategy (New 1987 and references therein).

We report herein four supposed immature bark lice inclusions in Myanmar amber with a potential camouflaging or masking behaviour as all fossils described herein carry debris atop their back.

\section{Materials and methods}

\section{Material}

Three pieces of amber are in the centre of this study. All specimens are about 100 million years old Myanmar amber ("Burmese" amber from Hukawng Valley, Kachin State). Two specimens are part of the collection of one of the authors (PM) and are stored under accession numbers BUB 3177 (amber piece 1) and BUB 3344 (amber piece 3). Both pieces were purchased and legally exported.

The other piece (amber piece 2) is deposited in the collection of the Palaeo-Evo-Devo Research Group Collection of Arthropods, Ludwig-Maximilians-University of Munich, Germany (PED 0142). This specimen was legally purchased on ebay.com from the trader globalburmiteamber. 
Extant immature bark louse specimens are from the entomological collection of the Centre of Natural History (Centrum für Naturkunde or CeNak) of the University of Hamburg. Five specimens of the following four species were documented: Trichadenotecnum sexpunctatum (Linnaeus, 1758) (collection number ZMH_828540), two specimens of Amphigerontia bifasciata (Latreille, 1799) (one early immature instar with the collection number ZMH_828636 and one very late immature instar with the collection number ZMH_828634), Loensia fasciata (Fabricius, 1787) (collection number ZMH_828578) and Ectopsocopsis cryptomeriae (Enderlein, 1907) (collection number ZMH_828588).

\section{Methods}

The amber pieces described above were photographed using a Keyence VHX-6000 light microscope (equipped with 20-2000 times magnification lenses). To reduce reflections and enhance the contrast, the specimens were photographed with a drop of distilled water and an above placed cover slip. The microscope did provide an overall sharp image of the specimens by photographing in different focal planes (stacks) with different illuminations and then combined that to one single sharp image within the programme of the microscope.

The extant specimens were photographed with a Canon EOS 70D reflex camera equipped with an MP-E $65 \mathrm{~mm}$ macro objective and a Macro Twin Lite MT-24 EX flashlight for an overview image. All extant specimens were photographed under cross-polarised light in different focal planes (stacks) and then fused to single sharp images (compare e.g. Haug et al. 2011). The image data generated that way was then stacked with CombineZP and stitched (combining the different stacked images of one image) with Adobe Photoshop CS3.

All obtained images were optimised for colour balance, saturation and sharpness in Adobe Photoshop CS2 and CS4. Adobe Photoshop CS2 and CS4 were also used to arrange the figures.

\section{Results}

\section{Short overview of entomological terminology and the relevant usage herein}

The insect body is typically organised in three tagmata: the head (with six segments: ocular segment and post-ocular segments 1-5), the anterior trunk or thorax (with three segments: pro-, meso- and metathorax, post-ocular segments 6-8) and the posterior trunk or abdomen (with 11 segments: post-ocular segments 9-19). All trunk segments possess dorsal sclerotisations, the tergites, and ventral sclerotisations, the sternites. The thorax tergites are often called nota, singular notum (pro-, meso- and metanotum).

The elements of the insect walking appendage (post-ocular segments 6-8) have each an individual name, here from proximal to distal: subcoxa (possible coxa in other closely related forms of Euarthropoda; mostly incorporated into the body wall), coxa (most likely the basipod of closely related forms of Euarthropoda), trochanter, femur, tibia and tarsus (the latter often subdivided into tarsal elements; all these most likely representing the endopod).

Not all the bark lice described herein were accessible from a dorsal and ventral orientation due to its embedding amber. To clarify eventual misunderstandings in relative measurements, here is a short overview of what each term means in relation to the animal: Width is here understood as the latero-median axis on the body, length as the anteroposterior axis (or proximo-distal axis on appendages) and height as the dorso-ventral axis.

Herein we used insect terminology with corresponding neutral euarthropod terminology in brackets, to ensure mutual understanding within the whole arthropod community. Also terminology of Crustacea sensu lato (CT) is pointed out where it differs from insect terminology (IT), as Insecta is an in-group of Crustacea sensu lato.

\section{Specimen BUB 3177 (amber piece 1)}

Figures 1, 9

Taxa embedded incl. syninclusions. Psocodea (indet. sedis; bark louse $\mathrm{N}^{\circ} 1$ ), no syninclusions.

Description (Bark louse $N^{\circ} 1$ ). This bark louse (Fig. 1) is discernible from a dorsal and ventral view. Entire body length (without appendages) of $1.3 \mathrm{~mm}$ and about $0.7 \mathrm{~mm}$ wide at its widest.

Head-(comprising the ocular segment and post-ocular segments 1-5) with width of about $0.7 \mathrm{~mm}$, corresponding to about one half of the body length and similar to its body width at its widest. Length of head not clearly determinable due to the orientation of the specimen in the amber piece, though probably less than its width. Head triangular shaped in anterior view. Vertex (area between the lateral compound eyes) with two possible, antero-posterior oriented, slight grooves discernible at about one third the distance from the compound eyes medially. Anterior edge of vertex concave. Frons (anteriorly to vertex) brighter than vertex, but without exact boundary; frons convex posteriorly and concave anteriorly. Clypeus (anterior to frons) only discernible posteriorly, where convex. No ocelli discernible medially between the compound eyes, though not completely exclude-able. Overall shape and that of subsequent structures (mouth parts) not discernible. 


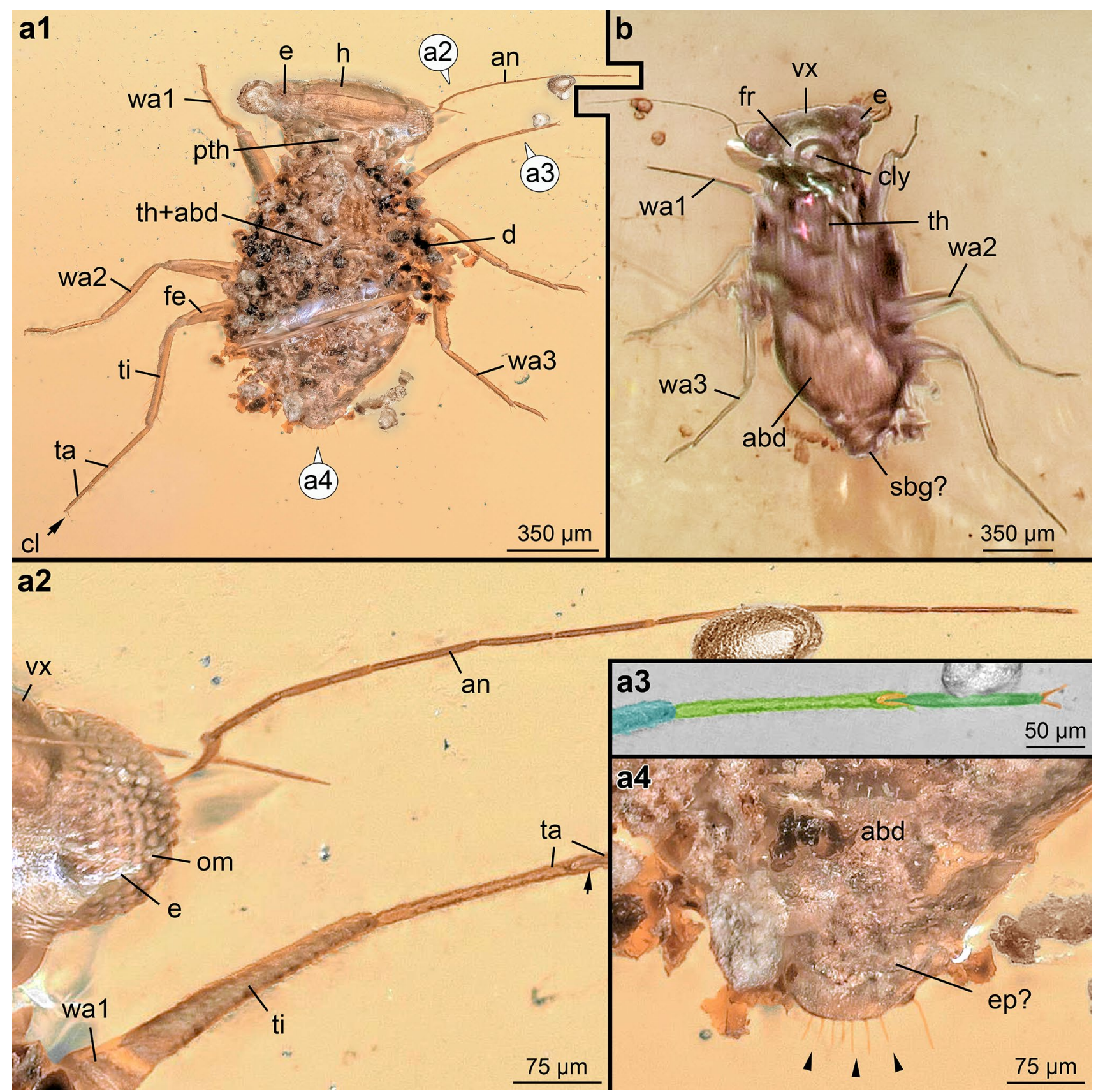

Fig. 1 Immature bark louse № 1 (collection number BUB 3177) with camouflage. a1. Dorsal overview. b. Ventral overview. a2. Detailed view on the right compound eye and antenna; arrow pointing towards tarsal joint membrane. a3. Detailed view on the distal part of the right first walking appendage; colour-marked parts: cyan tibia, brighter green proximal tarsus element, darker green distal tarsus element, yellow tarsal joint membrane, brown tarsal claws. a4. Detailed view

Compound eyes, laterally on the head (ocular segment), protruding slightly from the head capsule and rounded laterally; eyes about a quarter the width of the entire head and as long. About 60 ommatidia discernible on the right compound eye dorsally, so overall probably about 120 minimal, potentially more. on the posterior end of the abdomen; arrowheads pointing towards setae at posterior edge of the structure. Abbreviations: $a b d$ abdomen; an antenna (antennula); cly clypeus; $d$ debris; $e$ compound eye; $e p$ epiproct; $f e$ femur; $f r$ frons; $h$ head; om ommatidium; $p t h$ prothorax (first thorax segment); $s b g$ subgenital plate; $t a$ tarsus; th thorax; $t i$ tibia; $v x$ vertex; $w a$ walking appendage

Antennae (appendage of post-ocular segment 1; CT: antennula) discernible from dorsally, though attached to head further ventrally, probably underneath the compound eyes (Fig. 1a2). Elongated rectangular shaped in dorsal view, more than half as long as the entire body length, 
but not exceeding that. Most proximal elements of antenna (IT: scapus and pedicellus) not (clearly) discernible. Subsequent elements of antennae (IT: flagellomeres) elongated rectangular, much longer than wide; overall about twelve elements present on the right antenna, and probably also on the left antenna (but its more proximal portion not discernible).

Mouthparts not discernible due to layers in the amber obstructing the view.

Thorax-(post-ocular segments 6-8) usually consisting of three discernible units (pro-, meso- and metathorax); dorsally only prothorax distinct, meso- and metathorax (postocular segments 7-8) and segments of the abdomen (postocular segments 9-19) not visible as dorsally obscured by debris carried atop the bark louse and ventrally distorted by layers within the amber. Trunk (thorax and abdomen together) about $1.1 \mathrm{~mm}$ long. Pronotum (post-ocular segment 6) rectangular shaped in dorsal view, about two fifth the width of the head and slightly longer than half the length of the head. Posterior part of thorax (excluding prothorax) and abdomen together apparently oval shaped, with its widest point approximately in the middle of this "unit". Tapering from that point on posteriorly and also anteriorly, though less so than towards posterior.

Walking appendages (appendages of post-ocular segments 6-8; fore-, mid- and hindlegs) well and completely preserved. All discernible walking appendage elements elongated rectangular shaped in the dorsal view of the whole specimen. Femur, tibia and the bipartite tarsus discernible dorsally in detail (partly covered by carried debris, especially on the right side); ventrally all parts of the legs visible but strongly distorted, due to irregularities in the amber piece.

Foreleg (post-ocular segment 6; IT: prothoracic walking appendage) about $1.3 \mathrm{~mm}$ long. Visible part of the femur rectangular shaped in lateral view and about four times longer than wide. No spines or setae discernible; femur tapering slightly distally. Tibia proximally as wide as the femur and tapering distally to about half its proximal width. About six times longer than wide at its widest, with thin and rather short spines (or setae) discernible on the distal posterior part of the tibia. Tarsus with two elements (Fig. 1a3), slightly less wide than the tibia. Proximal tarsus element twice longer than the more distal one, but with similar width. Very distal end of proximal tarsus element with one spine. Distal tarsus element with two claws at its distal end, but no structures discernible in between.

Midleg (post-ocular segment 7; IT: mesothoracic walking appendage) slightly longer than the foreleg (but potentially also due to perspective/point of view); about $1.4 \mathrm{~mm}$ long. Visible part of the femur rectangular shaped in posterior view and about four times longer than wide. No spines or setae discernible; femur tapering slightly distally, though less so than the femur of the foreleg. Tibia proximally as wide as the visible, distal part of the femur and tapering slightly very distally and very proximally. About fourteen times longer than wide; with evenly spaced, thin and medium length setae discernible on the entire lateral edge of the tibia (setae about as long as the width of the tibia). Also with a thin, rather fine spine (or seta) discernible at the most disto-posterior part of the tibia. Tarsus with two elements and about two thirds the width of the tibia. Proximal tarsus element twice longer than the distal one, but with similar width. With two spines discernible at the very distal end of the proximal tarsus element respectively on its anterior and posterior corner; in between with a third spine discernible with about one third of the length of the other two spines. Similarly to tibia with evenly spaced, thin and shorter setae along its entire lateral edge; but setae thinner and shorter than the ones on the tibia. Distal tarsus element with two claws at its distal end, but no structures discernible in between.

Hindleg (post-ocular segment 8; IT: metathoracic walking appendage) presumably about one third longer than midleg, but of similar width overall; $1.8 \mathrm{~mm}$ long. Visible part of the femur rectangular shaped in posterior view and about three times longer than wide. No spines or setae discernible; femur tapering slightly distally, similarly to femur of midleg. Tibia slightly wider than tibia of midleg, but proximally as wide as the visible, distal part of the femur; tapering very slightly very distally and very proximally. About nine times longer than wide; also with evenly spaced, thin and medium length setae discernible on the entire lateral edge of the tibia; setae slightly short than width of tibia. Also with spine discernible at the most disto-posterior part of the tibia and two thinner spines (or setae) more proximally on the median edge of the tibia. Tarsus with two elements and about two thirds the width of the tibia. Proximal tarsus element more than twice longer than the distal one and also slightly wider. With two fine spines discernible at the very distal end respectively on its lateral and median corner; with a third spine (or seta) in between discernible with about one third the length of other two spines. With similarly to the tibia evenly spaced, thin and shorter setae along its entire lateral edge; these setae thinner and shorter than ones on tibia. Also with short spines along its median edge, more so distally than proximally. Distal tarsus element with two claws at its distal end, but no structures discernible in between.

Abdomen-(post-ocular segments 7-19), most parts dorsally non-discernible due to debris carried on top. Though posterior end slightly freed of carried debris with some structures discernible. Ventrally, abdomen anteriorly of apparently similar width to thorax, though tapering decidedly towards posterior, with most posterior region of abdomen only one 
third the width of the anterior, widest portion of the abdomen. Individual sternites not discernible due to distortion in the amber.

Trapezoid structure visible at very posterior end of abdomen with a rounded posterior edge from ventrally; apparently protruding slightly from abdomen, potentially the subgenital plate (presumably post-ocular segment 18 ). With dorsally discernible setae attached to the posterior edge of this (or associated) structure, probably epiproct and or paraprocts (both presumably post-ocular segment 19; Fig. 1a4). Eight setae present, four of which with very similar length, two of which very slightly longer than these four, one of which slightly shorter than these four and one of which about one-and-a-half times as long as these four setae. This last seta also situated more laterally on this structure than the other setae and thus also slightly set off from the remaining setae.

\section{Specimen PED 0142 (amber piece 2)}

Figures 2, 6, 7, 9

Taxa embedded incl. syninclusions. one Psocodean (indet. sedis; bark louse $\mathrm{N}^{\circ} 2$; Fig. 2) and many syninclusions (Figs. 6, 7) including a wasp (Hymenoptera) (Fig. 6a), dipteran(?) (Fig. 6f), two(?) mites (Fig. 6e, 6h), an unidentified euarthropodan exuvia(?) (Fig. 6c), the exuvia of an unidentified insect (Fig. 6b), fragments of a potentially dipteran (Figs. 6d, 7a) and insect fragments (wings and appendages) (Figs. 6g, 7b)

Description (Bark louse $N^{\circ}$ 2). This bark louse (Fig. 2) is discernible from an anterolateral and posterolateral view. Entire body length (without appendages) of about $0.9 \mathrm{~mm}$, though potentially longer or shorter due to the angle; its width even less discernible due to the angle.

Head - (comprising the ocular segment and post-ocular segments 1-5) triangular shaped in anterior view (Fig. 2a5), with width and length of about $0.4 \mathrm{~mm}$, corresponding to about one half of body length.

Compound eyes (ocular segment) tear shaped in anterior view and of about one third the length of the head capsule. Approximately about 130 ommatidia discernible on the right compound eye from this point of view; so potentially at least 260 overall present. Dorsally the vertex (area between compound eyes) with two distinct grooves discernible at about one third respectively from the lateral edge. With setae of medium to short length, especially on vertex. No ocelli medially between the compound eyes apparent. Labrum (ventrally attached to head) square shaped with rounded corners in anterior view and about as long as wide.

Attachment area of antennae (appendage of post-ocular segment 1; CT: antennula) ventrally to compound eyes; antennae approximately as long as entire body of bark louse and subdivided into probably about nine elongated rectangular shaped elements in anterior view. Two most proximal elements about equally long. Most proximal element (IT: scapus) about one-and-three-quarters longer than wide and tapering slightly distally. Subsequent element (IT: pedicellus) about two-and-two-thirds longer than wide and tapering drastically distally into a pointy tip. Subsequent elements (IT: flagellomeres) all of about same length, but tapering distally, so that distal width of the antennal flagellomeres about half that of the proximal width. First flagellomere about ten times longer than wide; subsequent element about 20 times longer than wide. The then subsequent two elements each about 27 times longer than wide; all subsequent elements not clearly discernible from each other, though potentially three distinct elements present. So potentially (at least) seven flagellomeres present and overall potentially nine antennal elements.

Mandible (appendage of post-ocular segment 3) tips discernible ventral to labrum. Apparently a heavily sclerotised structure.

Maxillary palps (part of appendages of post-ocular segment 4; IT: maxilla; CT: maxillula) with four discernible rectangular elements in anterior view. Most proximal (visible) element opposed to that more circular shaped in anterior view and about as long as wide. Subsequent element and all following elongated rectangular shaped in anterior view; second most proximal element more than two-anda-half times longer than wide. Subsequent element shorter than that and about twice longer than wide. Subsequent most distal element widening distally with a rounded distal edge and about twice longer than wide at its widest. Overall five elements. Further details of the mouthparts not visible due to orientation of specimen.

Thorax - segments (post-ocular segments 6-8) partially obscured dorsally by debris carried atop posterior part of bark louse and by head, so only walking appendages clearly discernible from this view, with exception of the prothorax. Prothorax tergite (pronotum; post-ocular segments 6) rectangular shaped with rounded corners in anterior view, also apparently elevated dorsally or set off from remaining thorax in anterior view and equipped with setae of varying lengths along its dorsal and lateral edge.

Foreleg (post-ocular segment 6; IT: prothoracic walking appendage) about $0.75 \mathrm{~mm}$ long from femur onward; more proximal elements not discernible. Femur widening proximally up to about the midpoint and then tapering distally in anterior view. About three-and-three-quarters longer than wide at its widest. Tibia proximally about the same width as femur distally, but widening slightly distally; very distally tapering into a pointy tip. About seven times longer than wide. With evenly spaced thin and short setae at its lateral 


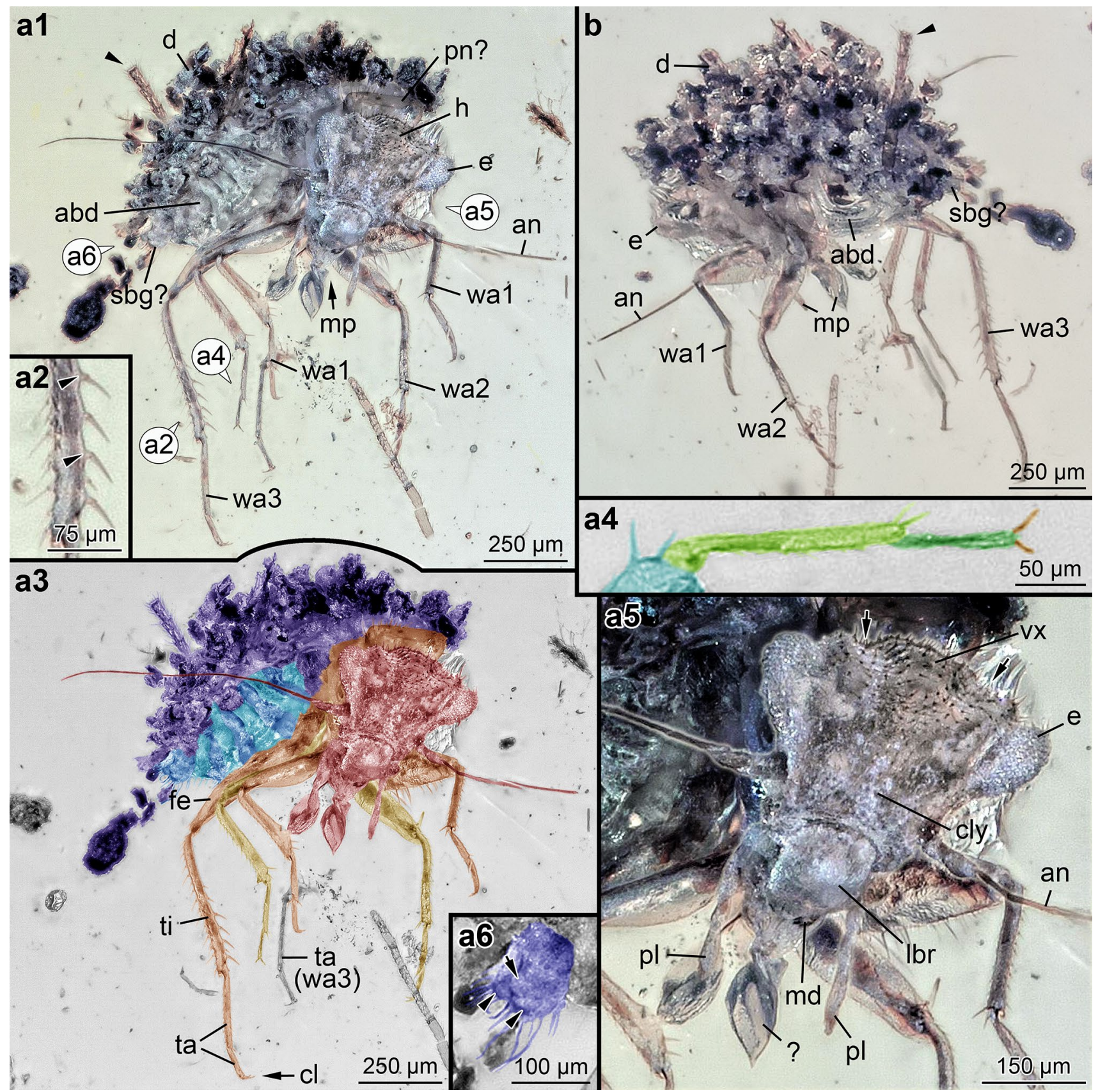

Fig. 2 Immature bark louse № 2 (collection number PED 0142) with camouflage. a1. Anterolateral overview; arrowhead pointing towards animal debris (potential antenna) carried atop the specimen. b. Posterolateral overview; arrowhead pointing towards animal debris (potential antenna) carried atop the specimen. a2. Detailed anterior view on tibial spines; arrowheads pointing towards (potential?) spine joint. a3. Colour-marked version of A: red head (ocular segment and postocular segments 1-5) with appendages, orange pro- and metathorax (post-ocular segments 6 and 8) with appendages, yellow mesothorax (post-ocular segment 7) with appendages, blue discernible parts of the abdomen, violet debris carried atop bark louse. a4. Detailed view on the distal part of the right walking appendage; colour-marked parts: cyan tibia, brighter green proximal tarsus element, darker green distal tarsus element, brown tarsal claws. a5. Detailed view of the head; arrows pointing towards grooves in the vertex of the head; question mark at peculiar structure potentially associated with mouth parts. a6. Detailed view of posterior end of abdomen; colour-marked last potential abdominal segment; arrow pointing towards medial lobular structure; arrowheads pointing towards posterior lateral paired lobular structures. Abbreviations. abd abdomen; an antenna (antennula); cly clypeus; $d$ debris; $e$ compound eye; $f e$ femur; $h$ head; $l b r$ labrum; $m d$ mandible; $m p$ mouth parts; $p l$ palp; $p n$ pronotum (prothoracic tergite); sbg subgenital plate; $t a$ tarsus; $t i$ tibia; $v x$ vertex; $w a$ walking appendage 
edge and two bigger and longer setae (or spines) on its distal median edge. Tarsus with two elements. Proximal tarsus element about one third the width of tibia and about seven times longer than wide. Also with evenly spaced thin and short setae at its lateral edge and a medium length seta at its distal most median edge. Distal tarsus element as wide as preceding element, but only about three quarters as long. About six times longer than wide. With two claws at its distal end, but no structures discernible in between.

Midleg (post-ocular segment 7; IT: mesothoracic walking appendage) apparently about as long as foreleg (but length potentially misleading due to perspective/view); about $0.85 \mathrm{~mm}$ long from femur onwards. Femur about sevenand-a-half times longer than wide and tapering slightly very distally in anterior view. Subsequent element (tibia) proximally about half as wide as femur, but widening very slightly distally and also tapering very distally into pointy tip. About eight-and-two-third times longer than wide. With evenly spaced thin and medium length setae at its lateral edge and two bigger and longer setae (or spines) on its distal median edge. Tarsus with two elements (Fig. 2a4). Proximal tarsus element about one third the width of the tibia and almost eleven times longer than wide. With two medium length setae at its distal most median edge. Distal tarsus about three quarters the width of the preceding element, but only about two thirds as long; about twelve times longer than wide. With two claws at its distal end but no structures discernible in between.

Hindleg (post-ocular segment 8; IT: metathoracic walking appendage) presumably about one third longer than midleg, but of similar width overall; about $1.1 \mathrm{~mm}$ long from the femur onwards. Femur tapering distally and potentially more than six times longer than wide at its widest discernible point in anterior view. Tibia proximally about the same width as the femur very distally, but widening very slightly distally and very distally tapering into pointy tip. About seven times longer than wide. With evenly spaced medium length setae at its lateral edge and four bigger and longer spines with a thickened proximal region on its more distal median edge (Fig. 2a2). Also with three setae, similar to those on the lateral edge, on the more distal portion of the median edge. Tarsus with two elements. Proximal tarsus about two thirds the width of the tibia and about eleven times longer than wide. With evenly spaced thin and small setae along its median and lateral edge and with a slightly thicker seta (than other setae of this element) at its distal most median edge. Distal tarsus only slightly less wide than preceding element, and more than half as long as that as well. About eight times longer than wide and with two claws at its distal end, but no structures discernible in between.

Abdomen-(post-ocular segments 9-19) apparently overall oval shaped in anterio-ventral view. Tergites of abdomen covered by debris, so segments only discernible ventrally, but in anterior view. Sternites of post-ocular segment 9-17 visible, each distinctly wider than long. Cuticula with several setae, more so posteriorly than anteriorly (though potentially perspective issue, as not all sternites clearly discernible). Most posterior sternite (presumably post-ocular segment 18; IT: subgenital plate) square shaped in anterio-ventral view with many medium length setae at its posterior edge and also three lobular structures at the medio-posterior portion of it (Fig. 2a6). Sternite slightly wider than long.

Remarks. The wasp (Fig. 6a) is probably a representative of Chrysidoidea (Apocrita). The insect fragments (wings and appendages) (Figs. 6g, 7b) are potentially parts of an adult representative of Psocodea (see further in discussion). The syninclusions of this amber piece are not in overly spatial closeness to one another.

\section{Specimen BUB 3344 (amber piece 3)}

Figures 3, 4, 5, 9

Taxa embedded incl. syninclusions. two Psocodean (indet. sedis; bark louse $\mathrm{N}^{\circ} 3$ and 4; Figs. 3, 4), one beetle larva (Figs. 4b1, 5a), one potential harvestmen (Figs. 3a1, 3b, 5b) and two mites (Figs. 3a1,b, 5c)

Description (Bark louse $N^{\circ} 3$ ). This bark louse (Fig. 3) is discernible dorsolaterally and ventro-laterally. Entire body length (without appendages) of $0.7 \mathrm{~mm}$; width not discernible due to angle.

Head-(comprising the ocular segment and post-ocular segments 1-5) tear shaped in lateral view (Fig. 3a5), about $0.3 \mathrm{~mm}$ long; width is not discernible due to angle. Vertex (between lateral compound eyes) with two possible, antero-posteriorly oriented, slight grooves medianly. Frontal area (frons and clypeus) bulbous, i.e. prominently protruding anteriorly. Short setae all over head discernible.

Laterally with decidedly smaller compound eyes (ocular segment) than those of previous bark lice (Fig. 3a5), with a lower number of ommatidia (about 20 discernible, though an exact number is not determinable) and darker than the remaining parts of the head. Eyes oval shaped in lateral view. Region of ocelli (between compound eyes) not discernible due to angle and air bubble; presence or absence of ocelli thus not discernible as well.

Two antennae (appendage of post-ocular segment 1; CT: antennula) discernible, about as long as the entire body. Antenna elements all elongated rectangular shaped in lateral view with about seven elements, but exact number not determinable. Most proximal discernible two elements (right side) of antennae decidedly shorter, one element about eight times longer than wide and very slightly wider 


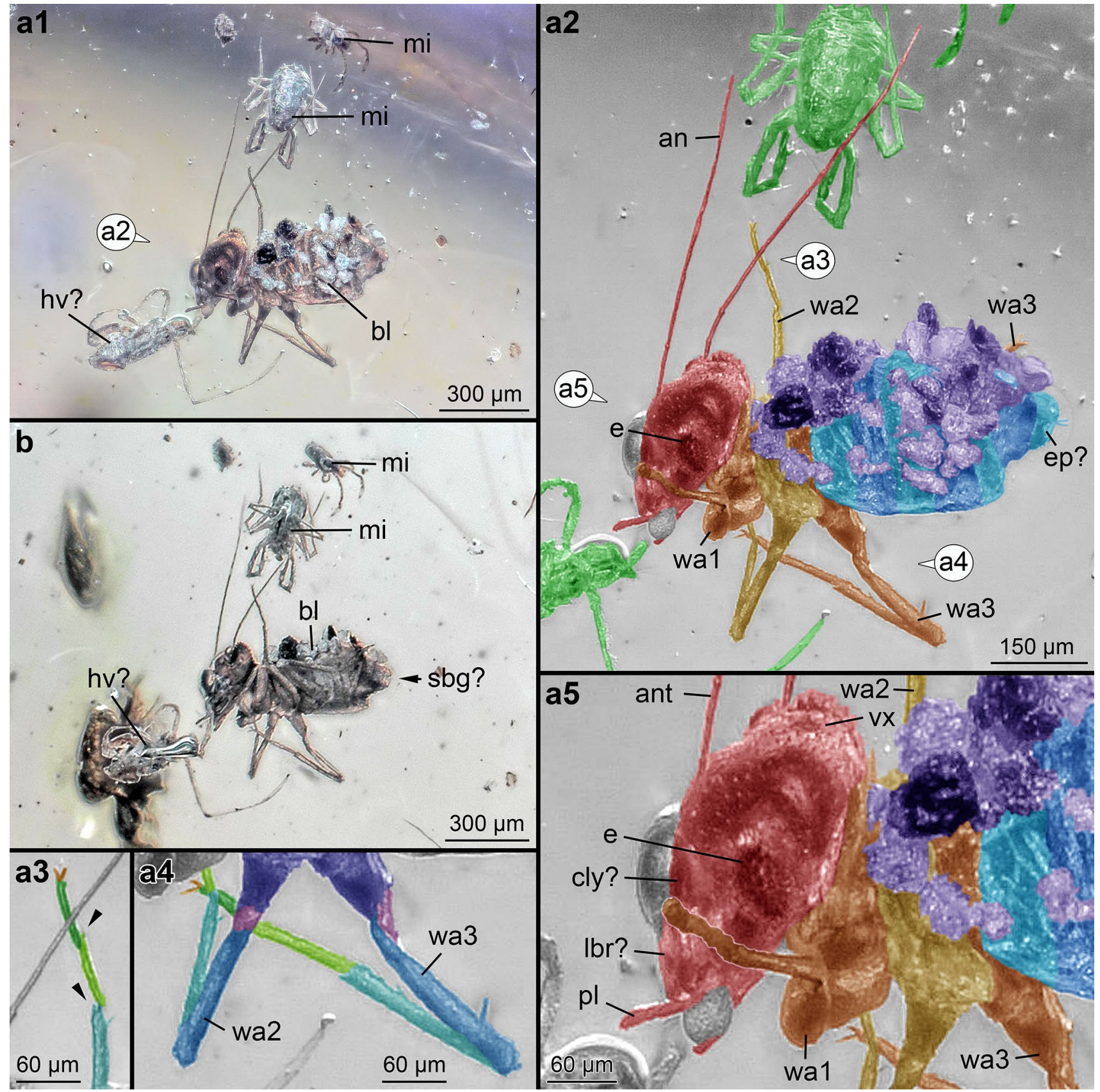

Fig. 3 Immature bark louse № 3 (of amber piece collection number BUB 3344) with syninclusions (mites, harvestman). a1. Dorsolateral (mirrored) overview of bark louse with spatially close syninclusions. a2. Colour-marked, detailed view of a1: red head (ocular segment and post-ocular segments 1-5) with appendages, orange pro- and metathorax (post-ocular segments 6 and 8) with appendages, yellow mesothorax (post-ocular segment 7) with appendages, blue discernible parts of the abdomen, violet debris carried atop bark louse, green syninclusions. b. Ventro-lateral overview of a1. a5. Detailed, colourmarked view of the head of A: red head (ocular segment and postocular segments 1-5) with appendages, orange pro- and metathorax (post-ocular segments 6 and 8) with appendages, yellow mesothorax (post-ocular segment 7) with appendages, blue discernible parts of

the abdomen, violet debris carried atop bark louse. a3,4. Detailed, colour-marked views on walking appendages of A. a3. Distal view on second walking appendage; arrowheads point towards spines of the tibia and the proximal tarsus respectively; cyan tibia, brighter green proximal tarsus element, darker green distal tarsus element, brown tarsal claws. a4. Overview of second and third walking appendage; violet-blue trochanter, pink joint membrane between trochanter and femur, indigo blue femur, cyan tibia, brighter green proximal tarsus element, darker green distal tarsus element, brown tarsal claws. Abbreviations. an antenna (antennula); $b l$ bark louse; cly clypeus; $e$ compound eye; $e p$ epiproct; $f e$ femur; $h v$ harvestman; $l b r$ labrum; $m i$ mite; $p l$ palp; $s b g$ subgenital plate; $t a$ tarsus; $t i$ tibia; $v x$ vertex; $w a$ walking appendage 


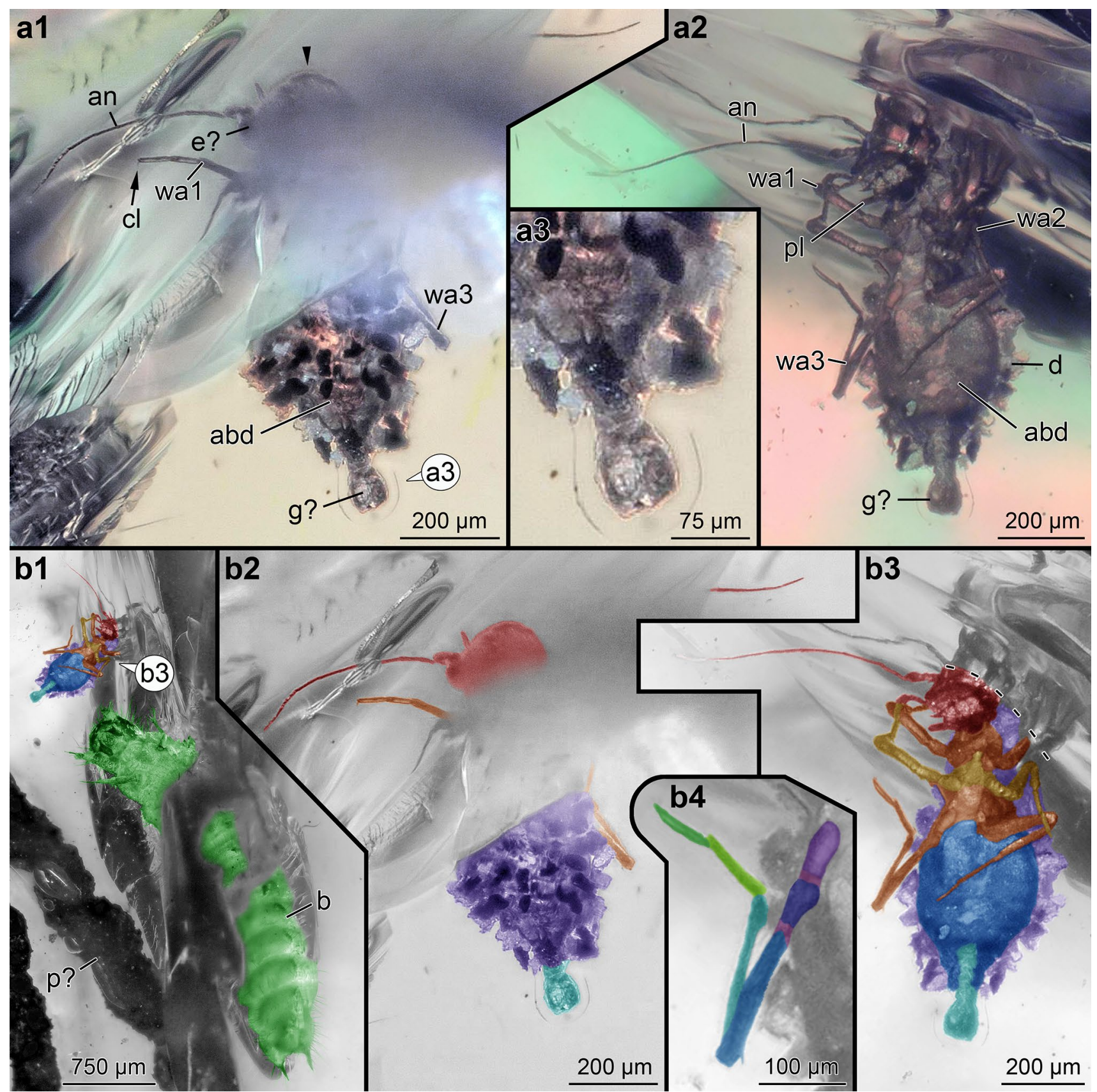

Fig. 4 Immature bark louse № 4 (of amber piece collection number BUB 3344) with beetle larva syninclusion. a1. Dorsal overview of bark louse; arrowhead pointing towards protruding clypeus(?). a2. Ventral overview of bark louse. a3. Detailed view of posterior abdomen end. b1. Overview of bark louse and spatially close embedded beetle larva. b2. Colour-marked version of a1: red head (ocular segment and post-ocular segments $1-5$ ) with appendages, orange proand metathorax (post-ocular segments 6 and 8) with appendages, yellow mesothorax (post-ocular segment 7) with appendages, cyan posterior abdominal structure, violet debris carried atop bark louse. b3. Colour-marked version of a2: red head (ocular segment and post- ocular segments 1-5) with appendages, orange pro- and metathorax (post-ocular segments 6 and 8) with appendages, yellow mesothorax (post-ocular segment 7) with appendages, blue discernible parts of the abdomen, cyan posterior abdominal structure, violet debris carried atop bark louse; dashed line indicates reflective structure through animal. b4. Detailed, colour-marked view of the third walking appendage in $\mathbf{a 2}$ and b3: violet coxa, dark blue trochanter, pink joint membrane, indigo blue femur, cyan tibia, brighter green proximal tarsus element, darker green distal tarsus element. Abbreviations. abd abdomen; an antenna (antennula); $b$ beetle larva; $c l$ claw; $d$ debris; $e$ compound eye; $g$ genitalia; $p$ plant; $p l$ palp; $w a$ walking appendage 


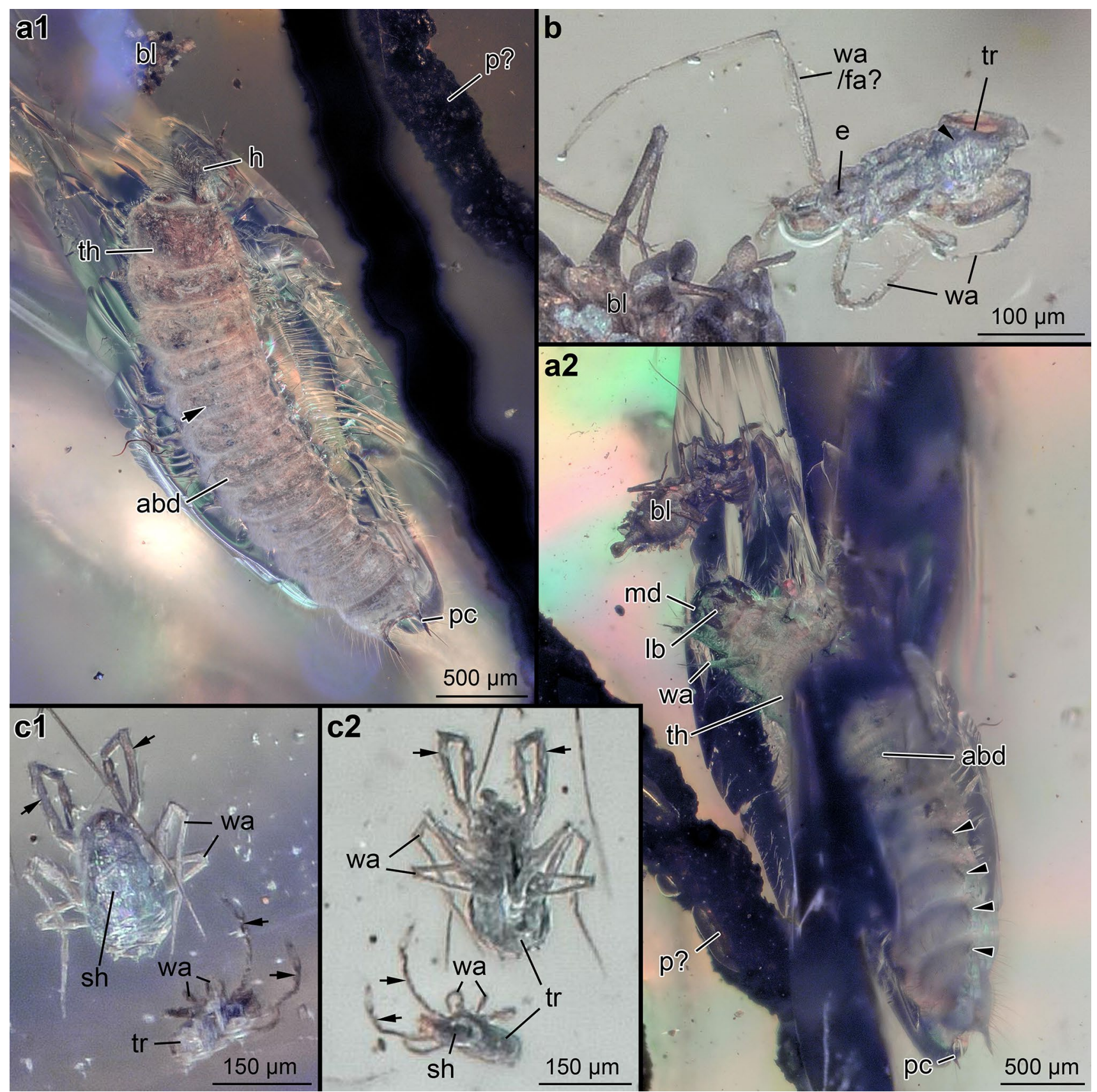

Fig. 5 Syninclusions of amber piece BUB 3344. a. Beetle larva with bark louse № 4. a1. Dorsal overview; arrow pointing towards groove in tergite. a2. Ventral overview; arrowheads pointing towards stigmata. b. Harvestman spatially close to bark louse № 3 in dorsal (mirrored) view; arrowhead pointing towards potential segment border. c. Mites spatially close to bark louse № 3. c1. Dorsal view; arrows

than the distal elements. One of the distal elements about 19 times longer than wide; all of apparently equal length.

Two potential palps discernible of mouth parts, presumably representing maxillary palps (part of appendages of post-ocular segment 4 (IT: maxilla; AT: maxillula). Rectangular shaped in lateral view, but tapering towards the pointing towards first apparent appendages. c2. Ventral view; arrows pointing towards first apparent appendages. Abbreviations. abd abdomen; $b l$ bark louse; $e$ eye; $f a$ feeler appendage; $h$ head; $l b$ labium; $m d$ mandible; $p$ plant; $p c$ pincers; $s h$ shield; th thorax; $t r$ trunk; $w a$ walking appendage

distal tip; individual elements not discernible. Other parts of mouthparts not discernible due to air bubble obstructing view in that region.

Thorax-segments (post-ocular segments 6-8) about a fifth of entire body length and about $0.12 \mathrm{~mm}$ long totally. 


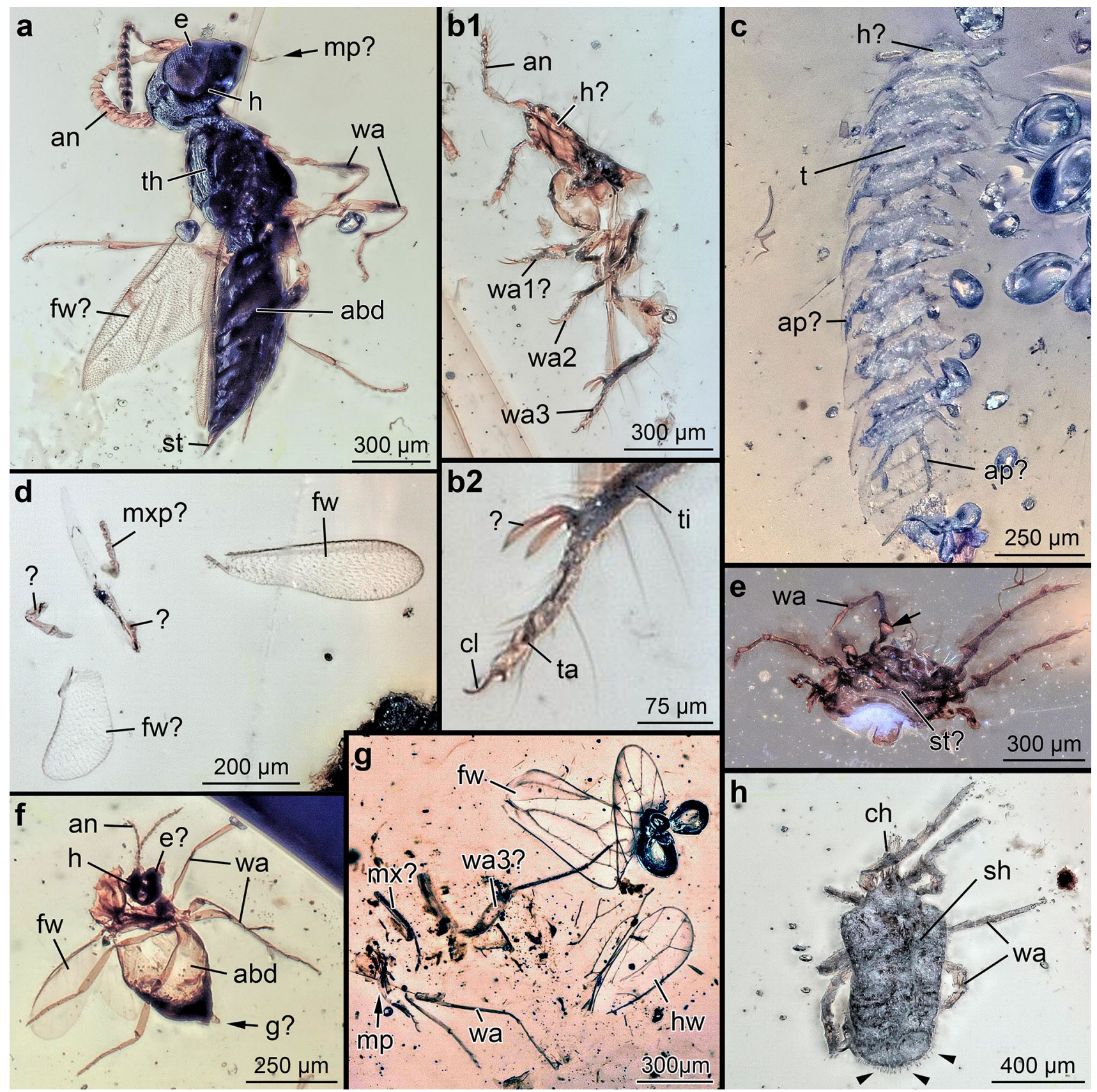

Fig. 6 Syninclusions of amber piece PED 0142. a. Wasp (Hymenoptera, Chrysidoidea). b1. Insect exuvia. b2. Detailed view of the third walking appendage of b1. c. Unidentified euarthropodan exuvia. d. Potential dipteran wing and mouth parts; question marks point towards unidentified structures, potentially associated with its mouth parts. e. Anterior part of a possible mite; arrow pointing towards enlarged potential joint area of appendages. f. Potential dipteran. g.

Dorsally, pro-, meso- and metanotum obscured by debris carried atop posterior part of bark louse.

Walking appendages (appendages of post-ocular segments 6-8; fore-, mid- and hindlegs) well and completely
Potential fragmentary psocodean appendages and wings. h. Mite; arrowheads pointing towards setae at posterior end of mite. Abbreviations. abd abdomen; an antenna (antennula); ap appendage; $c h$ cheliceres; $\mathrm{cl}$ claw; $e$ compound eye; $f w$ forewing (mesothoracic wing); $g$ genitalia; $h$ head; $h w$ hindwing (metathoracic wing); $m p$ mouth parts; $m x$ maxilla (maxillula); mxp maxillary palp; sh shield; st sternum; $t$ tergite; $t a$ tarsus; $t h$ thorax; $t i$ tibia; $w a$ walking appendage

preserved and all discernible elements elongated rectangular shaped in lateral view (Figs. 3a3, a4).

Length of foreleg (post-ocular segment 6; IT: prothoracic walking appendage; Fig. 3a2, a5) not clearly determinable due to orientation, but approximately about $0.2 \mathrm{~mm}$ 

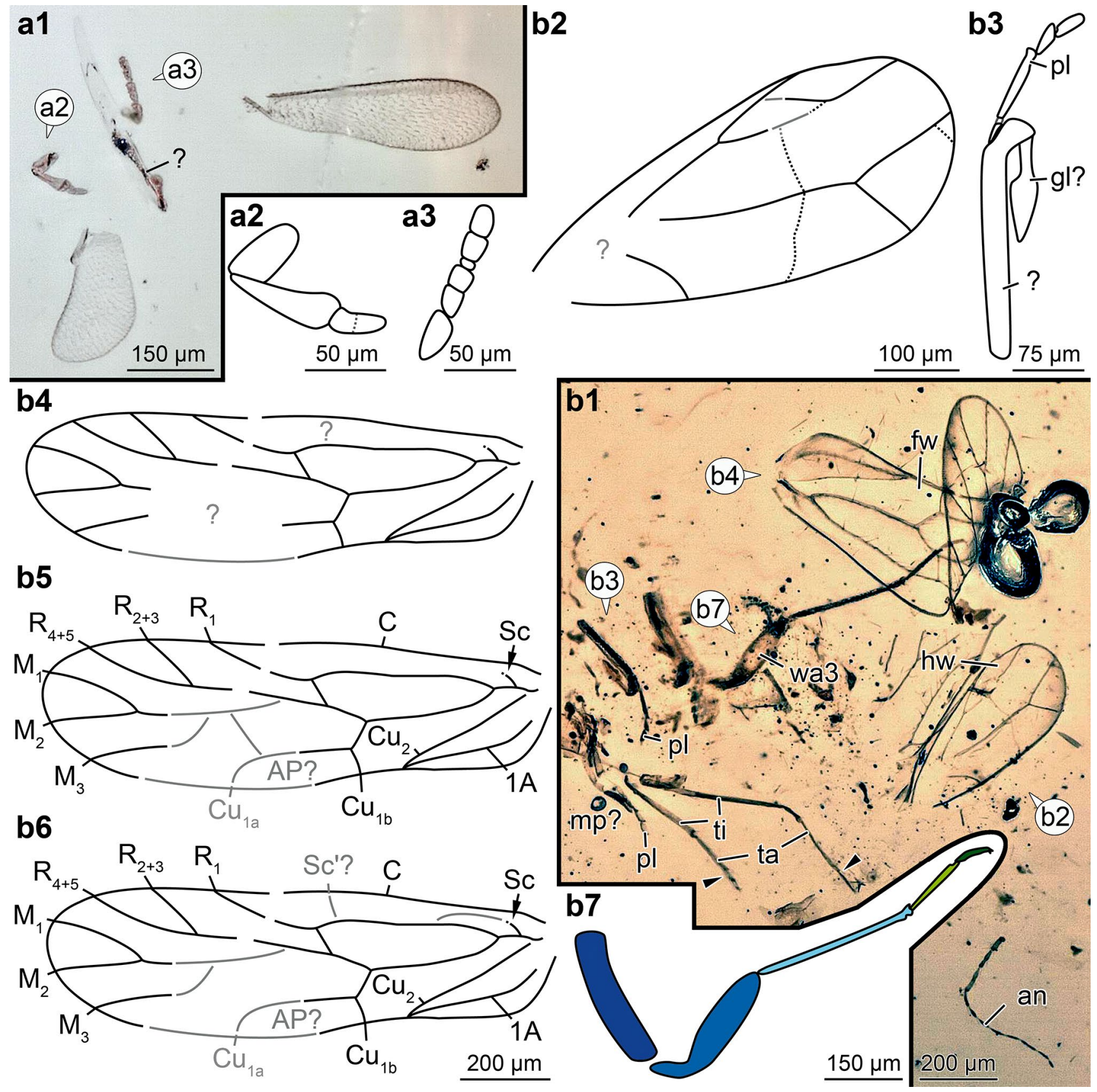

Fig. 7 Fragmentary syninclusions of amber piece PED 0142. a. Potentially dipteran fragments. a1. Overview photograph; question mark points toward structure potentially associated with mouth parts. a2,3. Detailed drawings of potential mouthparts of a1. a2. Potentially galea(?) (endopod of the maxilla (maxillula)). a3. Potentially maxillary palp (exopod of the maxilla (maxillula)). b. Possible psocodean fragments. b1. Overview of fragments; arrowheads pointing to joint of the tarsi. b2. Drawing of the smaller, potentially hindwing (metathoracic wing) with potential (not discernible) venation in grey of b1; question mark at unclear area of the wing. b3. Drawing of mouth part fragments, potentially the maxilla (maxillula) of b1.; question mark at proximal(?) element. b4. Drawing of the bigger, potentially forewing (mesothoracic wing) of b1; question marks at unclear or

obscured areas of the wing. b5-6. Different interpretations of the venation pattern in the non-discernible area in grey of the forewing drawing in b4. b5. Restorative drawing with interpretations of the cross-vein connecting the Media and Areola postica and very short Subcosta. b6. Restorative drawing with interpretations of no connection between the Media and Areola postica and longer Subcosta. b7. Colour-marked drawing of the walking appendage of b1: dark blue trochanter, indigo blue femur, cyan tibia, bright green proximal tarsus element, dark green distal tarsus element; at the distal tip of the distal tarsus element are two small claws. Abbreviations. $A$ anal vein; an antenna (antennula); $A P$ Areola postica; $C$ Costa; $C u$ Cubitus; $f w$ forewing; $g l$ galea; $h w$ hindwing; $M$ Media; $m p$ mouthparts; $p l$ palp; $R$ Radius; $S c$ Subcosta; $t a$ tarsus; $t i$ tibia; $w a$ walking appendage 
long. Most proximal part seemingly enlarged, almost as wide as prothorax at its longest and oval shaped in lateral view; though also potentially due to perspective. This proximal element, probably either femur or trochanter, also about twice longer than wide. Appendage tapering drastically towards distally, to about one quarter the width at the 'midpoint' of the appendage, where forth it does not taper any longer. Proximal elements of appendage obscured by distal parts of it, so no more discernible. Third most distal element, probably tibia, apparently not rectangular but oval shaped in median view and only slightly longer than wide. Most distal two elements, probably two tarsus elements, both of equal length and width, each element being more than five times as long as wide. No claw discernible on right foreleg.

Midleg (post-ocular segment 7; IT: mesothoracic walking appendage; Figs. 3a3, a4) about $0.4 \mathrm{~mm}$ long. Most proximal element (coxa) trapezoid shaped in lateral view and about half as wide distally than proximally and as long as wide at its widest proximally. Trochanter circular shaped in lateral view, so as wide as long and about as wide as the preceding element at its distal edge. Femur elongated rectangular shaped in lateral view and widening slightly distally, though very distally pointy. About six times longer than wide. Tibia also elongated rectangular shaped in medio-lateral view and seemingly tapering distally. With potential setae present at its anterior edge, more proximal than distal. One more prominent seta discernible at its distal posterior edge and at its (anterior) most distal tip also respectively. Element about eleven times longer than wide and about as long as preceding element, though only three quarters as wide as the same. Tarsus with two rectangular shaped elements in medio-lateral view. Proximal tarsus element tapering distally and with a short spine(?) at its (posterior) most distal tip. Tarsus elements of similar width and length; both about half the width of the tibia and shorter than the discernible parts of the tibia. Distal tarsus element with two claws discernible at the distal tip, but no structures discernible in between.

Hindleg (post-ocular segment 8; IT: metathoracic walking appendage; Fig. 3a4) about $1.1 \mathrm{~mm}$ long. Coxa about one-and-a-half times longer than wide; widest at its proximal connection to body and tapering slightly distally. Trochanter apparently half-circular shaped in this view and about three times longer than wide at its widest midpoint. Femur elongated rectangular shaped in antero-lateral view and widening drastically from its pointy, proximal portion; with a seta recognizable at a more distal part of its posterior edge and also with a short spine(?) at its distal edge. Femur about seven and a quarter times longer than wide. Tibia also elongated rectangular shaped in medio-lateral view with potential setae present at its anterior edge and also with a more prominent seta at its distal posterior edge. Element about eleven times longer than wide and about as long as the preceding element, though only three quarters as wide as the same. Tarsus with two elongated rectangular shaped elements in medio-lateral view. Proximal tarsus about three quarters as wide as tibia and apparently sixand-a-half times longer than wide. Distal tarsus slightly shorter than proximal tarsus with two claws discernible at the distal tip, but no structures discernible in between.

Abdomen-(post-ocular segments 9-19) overall oval shaped and about $0.4 \mathrm{~mm}$ long. Individual segments of abdomen not clearly discernible, partially due to debris carried atop the bark louse, though apparently with at least seven visible, rectangular shaped segments (Fig. 3a2, b). Segments decidedly wider than long.

Most posterior discernible abdominal sternite (presumably post-ocular segment 18 ; IT: subgenital plate) consisting of two lobular structures with a clear median separation between these two (Fig. 3b). About three-and-a-half times wider than long.

Description (Bark louse $N^{\circ} 4$ ). This bark louse (Fig. 4) is discernible dorsally and ventrally, though partially obscured by irregularities and layers within the amber. Entire body length (without appendages) of about $0.9 \mathrm{~mm}$ and about 0.25 $\mathrm{mm}$ wide at its widest.

Head - (comprising the ocular segment and post-ocular segments 1-5) probably triangular shaped with rounded anterior corner in dorsal view (Fig. 4a1, b2). About $0.25 \mathrm{~mm}$ wide. Compound eyes not visible due to the irregularities in the amber.

Two antennae (appendage of post-ocular segment 1; CT: antennula) discernible with elongated rectangular elements in dorsal view. Most proximal visible element of antenna about one-and-a-half times the width of the distal elements. More distal elements of antenna about half as wide as the most proximal (dorsal) element and about one third (where discernible) longer than that same element. Antenna with at least six distinguishable elements, possibly more originally.

Mouthparts not identifiable, besides a palp being potentially part of the maxilla (post-ocular segment 4; CT: maxillula). Palp with rounded tip and longer than wide in ventral view.

Thorax-segments (post-ocular segments 6-8) about one fifth of entire body length and about $0.2 \mathrm{~mm}$ long. Dorsally, pro-, meso- and metanotum not discernible due to layers in the amber piece, but seemingly covered by debris as discernible laterally in ventral view (Fig. 4a2, b3). Sternites pentagonal shaped in ventral view with one tip pointing anteriorly and enlarged laterally. 
Walking appendages (post-ocular segments 6-8; fore-, mid- and hindlegs) well and completely preserved. All discernible elements elongated rectangular shaped.

Length of foreleg (post-ocular segment 6; IT: prothoracic walking appendage) not clearly determinable due to perspective, though probably about $0.4 \mathrm{~mm}$ long. Coxa circular shaped in ventral view and about as long as wide. Trochanter rectangular shaped in median view, about twice longer than wide and slightly longer than the coxa. Femur also elongated rectangular shaped in median view, as wide as, but twice longer than the trochanter. Tibia only slightly discernible and approximately rectangular shaped in latero-posterior (Fig. 4a2, b3) and also latero-anterior (Fig. 4a1, b2) view and about as wide as the femur, length not determinable. Tarsus with two elements and also rectangular shaped in latero-anterior view. One claw discernible in latero-anterior view, but probably two. Structures between the claws indeterminable.

Midleg (post-ocular segment 7; IT: mesothoracic walking appendage) slightly longer than foreleg, but exact length not clearly determinable due to perspective. Coxa of midleg more oval shaped in ventral view and almost twice longer than wide (at its widest point); situated at the latero-posterior part of the mesothoracic sternite. Trochanter rectangular shaped in median view, about as long as the coxa and as wide as the most distal part of the coxa. Femur also rectangular shaped in median view, twice longer than the trochanter and about as wide as that as well. Tibia also rectangular shaped in latero-posterior view, about two thirds the width of the femur, length not determinable; with two spines at its most distal posterior and anterior corner. Tarsus with two elements; about two thirds the width of the tibia. Proximal element one quarter shorter than distal element. Claws not discernible.

Hindleg (post-ocular segment 8; IT: metathoracic walking appendage; Fig. 4b4) longer than midleg and $0.7 \mathrm{~mm}$ long. Coxa rectangular shaped in ventral view and widening slightly towards distally; situated at the latero-posterior part of the metathoracic sternite. Coxa almost three times longer than wide. Subsequent element (trochanter) similar to coxa in shape and measurements, though with slight round protrusion at its proximo-posterior edge. Femur also rectangular shaped in median view and widening slightly distally; with a seta discernible at its distal posterior edge. Femur wider and longer than trochanter, about seven times longer than wide at its widest. Tibia also rectangular shaped in lateral view, about as long as the femur, but only half as wide. Tarsus with two elements, both elongated rectangular shaped in lateroposterior view. Proximal tarsus slightly longer than distal one, but similarly wide, also as wide as the tibia and together about as long as the tibia. No claw discernible at the distal tip of the hindleg.
Abdomen - (post-ocular segments 9-19) overall oval shaped and $0.6 \mathrm{~mm}$ long; as wide as the metathorax anteriorly and widening until about one third the length of the abdomen and then tapering posteriorly, more drastically so at the last quarter of the abdomen. The abdominal segments dorsally covered by debris; individual segments also not clearly discernible ventrally.

Abdomen with protrusion at its posterior-most end which thickens more posteriorly (Fig. 4a3). Ventrally beginning within the last quarter of the abdomen, elongated rectangular shaped there and about twice longer than wide. Protrusion outside the abdomen also rectangular shaped with rounded corners; protruding about $0.1 \mathrm{~mm}$ out of the abdomen. With a very thin, setae-like structure surrounding most of the posterior structure and connecting to parts of the debris of the abdomen, though questionable whether actual structure of the animal or just structure within the amber due to movement of the animal during embedding.

Remarks. Bark louse № 3 (Fig. 3) is in close spatial proximity to two mites andone putative harvestmen (Figs. 3a1, b, 5b, c) and Bark louse № 4 (Fig. 4) is very close to one beetle larva (Figs. 4b1, 5a).

\section{Discussion}

\section{Identification of syninclusions}

The group Psocodea ( $\approx$ Psocoptera including Phthiraptera, see discussion below) has three distinct autapomorphies (after Ax 2000): an apparatus for oral uptake of water vapour from the atmosphere, a rupture-facilitating mechanism at the base of the antenna and anchoring of the fore- and hindwings through a binding device.

The apparatus for water vapour uptake is internal and mouthparts of the bark lice described herein were not (clearly) discernible. Therefore this character could not be observed in the specimens. The rupture-facilitating mechanism at the proximal part of the antenna is a very delicate and small cuticular feature and could also not be observed herein. And the anchoring of the wings could also not be observed as the bark lice herein do not have wings.

Thus unequivocally identifying the specimens as representatives of Psocodea (based on autapomorphies) is not possible. Yet, there are other features, which are in their combination characteristic for bark lice (compare e.g. Baz 2008), and which could be observed in the specimens studied herein: the overall body form and shape, their rather small size and more so the reduction to only two tarsus elements and the general slender appearance of the legs, longer hindlegs and the shape of the head with a characteristic Y-shaped epicranial suture frontally and a (prominent) bulging (post-)clypeus. 


\section{Potential position within Psocodea}

The phylogenetic relationships within Psocodea are still highly debated. The traditional division into two groups, Psocoptera and Phthiraptera has been rejected by many authors, as most phylogenetic analysis show a paraphyly of "Psocoptera" or even of both groups (e.g. Johnson et al. 2004; Murrell and Barker 2005; Yoshizawa and Johnson 2006). Phthiraptera (if monophyletic, see below) is deeply nested within Psocoptera. Hence, either Psocoptera is considered as not valid or as a synonym of Psocodea.

In more recent studies Psocodea has been postulated to consist of three (but sometimes four) major groups (see e.g. Yoshizawa and Lienhard 2010): Psocomorpha, Trogiomorpha, Troctomorpha and Phthiraptera. Two of these groups are widely accepted as monophyletic: Psocomorpha (Mockford 1967; Johnson and Mockford 2003; Yoshizawa 2005) and Trogiomorpha (Mockford 1967; Perrichot et al. 2003; Yoshizawa et al. 2006). More difficult seems to be the groups of Phthiraptera (true lice or parasitic lice) and Troctomorpha.

As often with statements like "the group includes four major in-groups", taxonomic classification does not reflect the actual relationships. Such statements ignore sister-group relationships. It appears that Trogiomorpha is the sister-group to an unnamed group including all remaining representatives of Psocodea (e.g. Johnson et al. 2004). Within this unnamed group, Psocomorpha appears to be the sister-group to all remaining representatives, which have been traditionally considered as representatives of Troctomorpha and Phthiraptera. Troctomorpha is either not a valid group name or it has to include the true lice (e.g. Johnson et al. 2004), possibly as the sister-group to Liposcelidae (Johnson et al. 2018; see also discussion in Zrzavý 2008), yet then the sistergroup to Psocomorpha needs a new name. There are some phylogenetic analysis postulating a monophyletic group Troctomorpha without including Phthiraptera, yet these analysis did simply not include true lice in their analysis (Johnson and Mockford 2003; Yoshizawa et al. 2006). Finally some analysis have resolved Liposcelidae (and some minor other lineages) as deeply nested within Phthiraptera, making Liposcelidae either a group of highly derived true lice or makes Phthiraptera not valid. These findings have lead to the suggestion that parasitism evolved independently within Phthiraptera (Johnson et al. 2004), yet it cannot be easily excluded that the life style of representatives of Liposcelidae is indeed derived from a parasitic life style.

Due to this still ongoing discussion and the fact that information about the morphology of immatures can be rarely found in the literature, it is difficult to determine the potential position within Psocodea of the herein described specimens. Moreover, there is a lack of data of Cretaceous representatives of Psocodea in Myanmar amber, despite descriptions of adult forms of twenty-two species up to now (but see below; Ross 2020; Yoshizawa and Lienhard 2020). However, there are some indications which allow at least narrowing it down.

True lice are specialised in morphology to a parasitic lifestyle, including e.g. reduced compound eyes, dorsoventrally flattened head, antennae with three-five elements and/or massive tarsal claws (e.g. Durden 2019). The morphology of these forms differs significantly from the specimens reported here. Other groups within Psocodea are mostly distinguished by the number of antenna elements and labial palp elements and heavy sclerotisations on the hypopharynx (an internal mouth part functionally and developmentally associated with the mandible) or characters of the wings (New 1987; Smithers 1990). Neither the labial palps nor internal mouth part structures could reliably be observed in the bark lice described herein.

Based on antenna characters, an in-group position within Trogiomorpha is less likely based on their low antennal element number (more than 20 elements in Trogiomorpha vs. three-twelve in the herein described specimens; Smithers 1990). Yet, the number of antenna elements increases over development, which further complicates identification, if the specimens represent immatures (see discussion below). It has even been shown that disturbance of the antenna during post-embryonic development can decrease the number of antenna elements and their length in the adult (Seeger 1975). Additionally, the antennae seem to be brittle and are easily broken off (New 1987), so identification based solely on the number of antennal elements seems to be unreliable to a certain point.

The fossil record of bark lice in Myanmar amber has so far lead to with 22 formally described species (Ross 2020; Yoshizawa and Lienhard 2020). We cannot clearly identify the new specimens to one of the already formally described species as these are based on winged adults only (compare Ross 2020 and references therein; Yoshizawa and Lienhard 2020). One exception of this is the description of possible nymphs of true lice in Myanmar amber, but these differ markedly in general morphology (Gao et al. 2019).

The fossils reported herein are furthermore special in apparently carrying small pieces of debris on their back, finely arranged or covering the entire surface. Comparable debris-carrying, masking or camouflaging behaviour among extant bark lice have been described for representatives of the groups Psocidae, Myopsocidae (both Psocomorpha), Amphientomidae and Troctopsocidae (Mockford 1974; Betz 1983; Thornton 1985; Henderson and Hackett 1986; Lienhard 1988; Baz 2008; Lienhard and Baz 2011). The specimens described herein cannot be reliably identified to 
one of these groups based on known characters, but can also not be ruled out, except for the group Amphientomidae (as none of the specimens possess scales on the body or combs on the forelegs; Smithers 1972).

Based on differences in morphology of the specimens, such as head shape, relation of head and body size, eyes and proportion of legs, it is unlikely that all the fossils represent conspecifics and it remains also possible that the preserved bark lice belong to different groups within Psocodea.

\section{Possible psocodean syninclusions (PED 0142)}

There are fragmentary remains of potentially psocodean origin (Figs. 6g, 7b) as a syninclusion of bark louse № 2 (PED 0142, Fig. 2), but not in close spatial proximity. These would be definite adult fragments, but it is not certain whether all these fragments belong to the same specimen or not, but it is at least not unlikely. These fragments share many characters that support the interpretation as parts of a representative of Psocodea: the overall shape of the walking appendages is similar and the wing venation is definite psocodean. Though further determination (especially under the assumption that all fragments belong to the same specimen or species) is not unequivocally possible, because regardless of its fragmentary nature even the forewing is not completely preserved and partly obscured.

There are two possible interpretations of the forewing (Fig. 7b4, b5, b6), depending on wing characters alone:

(1) There is a connection between the Media and the Areola postica (Fig. 7b5). This would mean that the individual is a representative of the group Psocidae (or Lachesillidae, if there is no crossvein connecting these two veins, but entirely connected) (after the key in Smithers 1990 as hereafter).

(2) The Areola postica is free, i.e. the Media is not connected in any way with the Areola postica (Figs. 7b6). This would make an in-group position within Epipsocidae, Mesopsocidae or Lachesillidae more likely. These possibilities all are dependant on a character state of two tarsal elements, as discernible within the appendages preserved closely nearby. All these are ingroups of the Psocomorpha. If there are three tarsal elements present, it could in turn also be an in-group of Prionoglarididae or Psyllipsocidae which are both ingroups of the Trogiomorpha. The fragmentary appendage of this possible psocodean adult (Fig. 7b) shows some similarities with the appendages of the immature psocodean (Fig. 2) preserved within the same amber piece. The overall shape and proportions appear similar, but there are two marked differences: The immature psocodean has a distinct row of spines on the tibia of the third walking appendage (Fig. 2a2); the presumed third walking appendage of the fragmentary psocodean adult (Fig. 7b1, b7) does not have such spines on its tibia. Also the shape of the tibia seems to differ between these two, though that could also be due to different perspectives.

\section{Immature vs. adult}

The distinction between immatures (nymphs, larvae) and mature adults (imago) among non-holometabolan forms of Insecta is only dependant on a few characters. Such immatures are mostly described as essentially adult-like with a few 'missing' features (but see e.g. Haug 2019, 2020). The most prominent features that are different between these immatures and adults are the wings (which are absent or not movable in immatures) and the genital structures (but see Hörnig et al. 2018). These structures develop and grow during post-embryonic development until they reach the adult form.

In bark lice immatures (compare also with Fig. 8) there are five other characteristics that help distinguishing them from adults: there are always two tarsus elements (two or three in adults except in true lice), the antennae are relatively shorter (compared to the adult) with fewer elements (especially in early instars) (Finlayson 1949), lack of ocelli and equally sized thorax segments (Smithers 1972). There are some species, where the ommatidia number of the compound eye increases during post-embryonic development (Kučerová 2007; Kučerová et al. 2009), though it is unclear whether this is true for all bark lice.

Indications for immature vs. adult of the herein described bark lice specimens:

(1) The herein described specimens possess all two tarsal elements, which could reflect an indication that they represent immatures. In many groups within Psocodea, except true lice (Durden 2019) and several psocomorphan groups, adults have three tarsal elements, so immatures of these can unequivocally be identified as such (Smithers 1972). Yet, since the phylogenetic position of the herein described specimens is unclear, this is only liminal applicable here.

(2) The antenna length and number of antenna elements is equally unreliable, as described above, and this mostly works when the species of the (supposed) immature has been determined. Lack of ocelli is not a characteristic of immature instars alone, as also wingless (apterous) adult bark lice do not have ocelli. Also the equally sized thorax segments may change during development, especially in immatures of winged adults (compare Sommerman 1943: pl. 2; also Fig. 8). Yet, at least two of the herein described specimens (bark louse No 3 and 


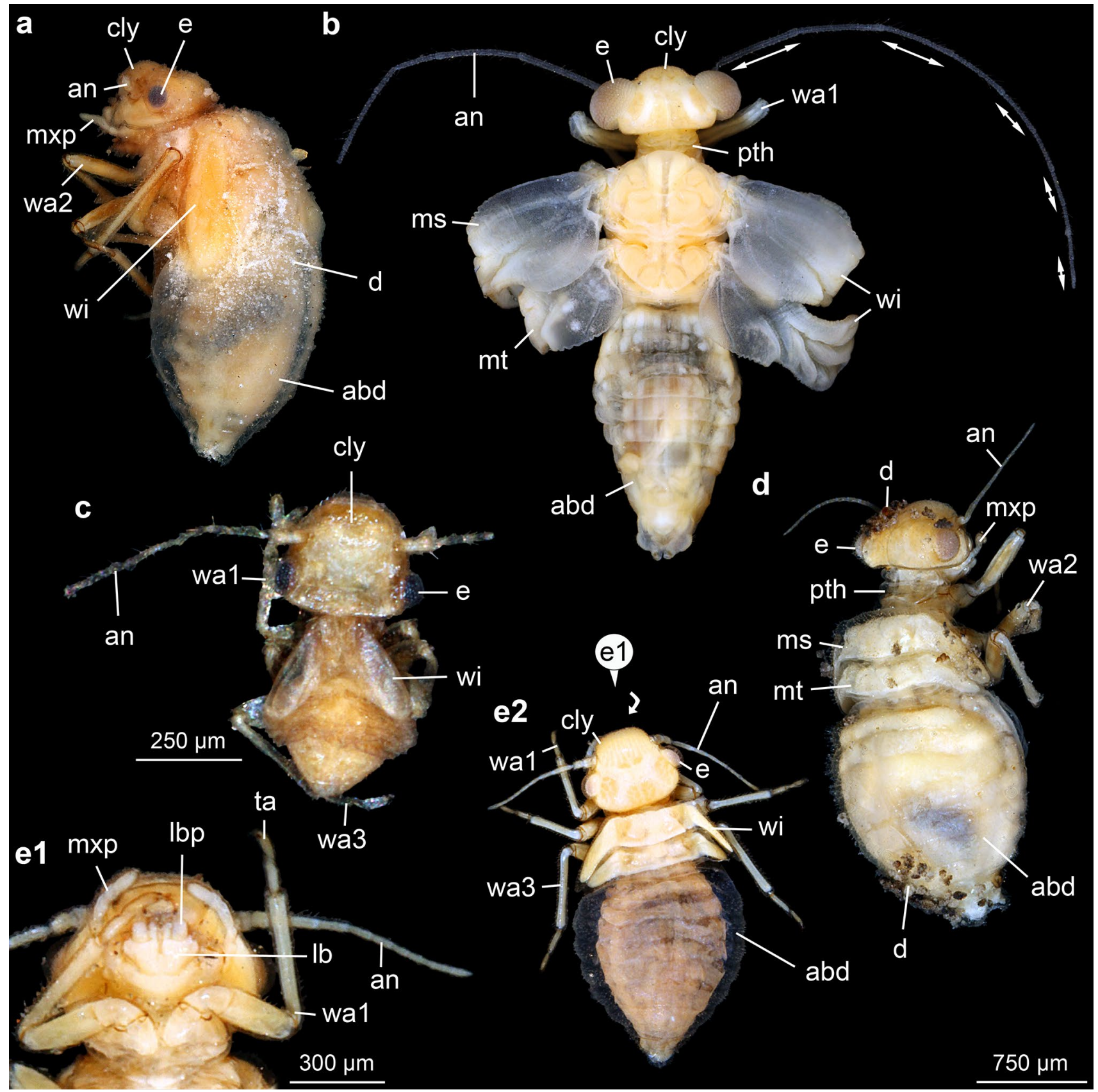

Fig. 8 Immature extant psocomorphan bark lice. a. Trichadenotecnum sexpunctatum (ZMH_828540) in latero-dorsal view. b,e. Amphigerontia bifasciata. b. Very late immature instar (ZMH_828634) in dorsal view; arrows delineate antenna elements. c. Ectopsocopsis cryptomeriae (ZMH_828588) in dorsal view. d. Loensia fasciata (ZMH_828578) in latero-dorsal view. e. Early immature instar (ZMH_828636). e1. Detailed ventral view of anterior region. e2. Dorsal overview. Abbreviations. abd abdomen; an antenna; cly clypeus; $d$ debris; $e$ eye; $l b$ labium; $l b p$ labial palp; $m s$ mesonotal wing anlage; $m t$ metanotal wing anlage; $m x p$ maxillary palp; $p t h$ prothorax; $t a$ tarsus; $w a$ walking appendage; wi wing anlagen

elements. All these are at least hints that these bark lice are potentially immatures. Though it has to be mentioned that not all adult bark lice are fully winged (macropterous), as there are brachypterous (reduced wings) or apterous (wingless) forms, usually as a sexual dimorphism. This seems to be not uncommon and some 


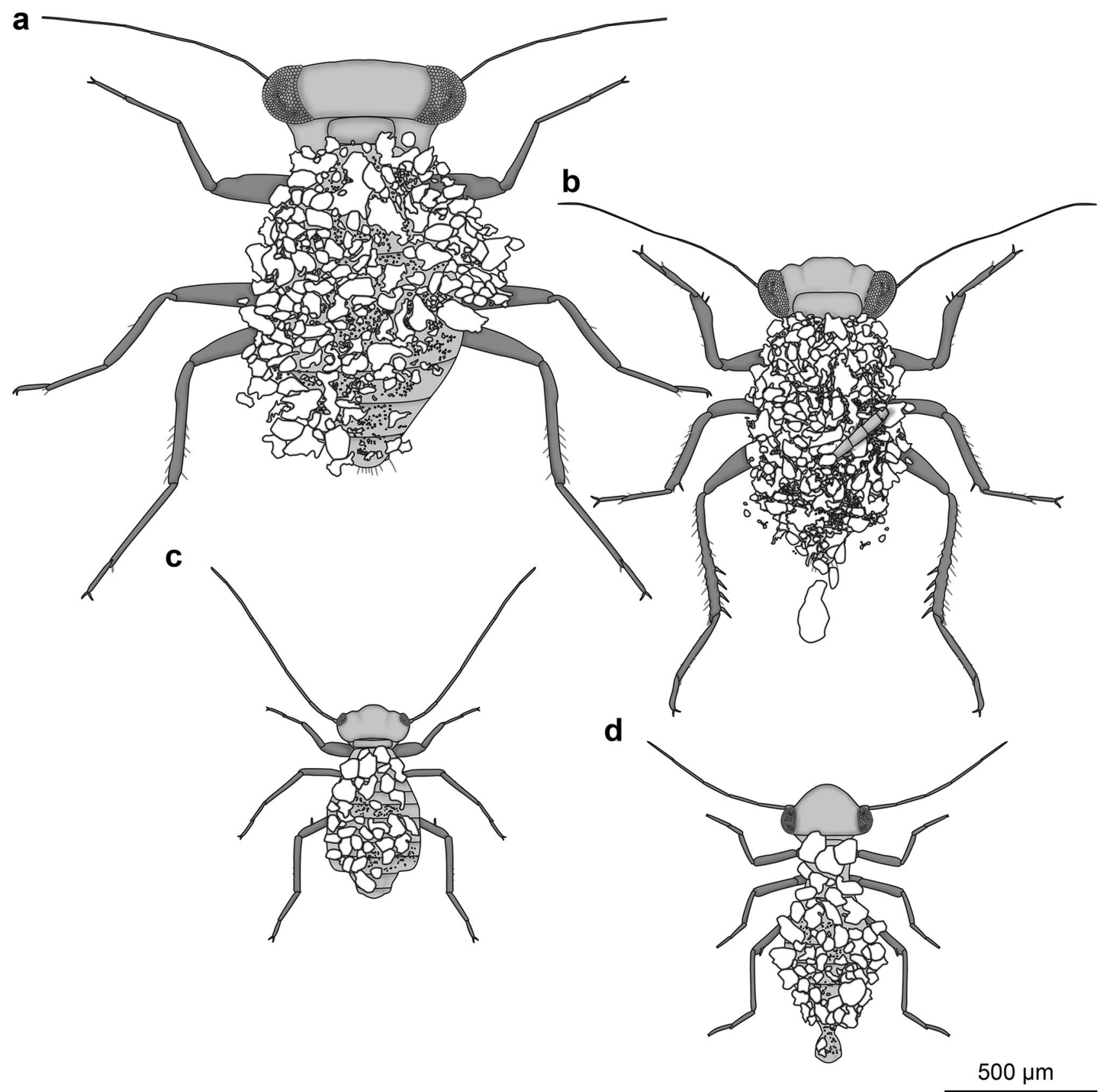

Fig. 9 Restorative drawings of immature fossil bark lice described herein in dorsal view. a. Bark louse № 1 of Fig. 1 (collection number BUB 3144). b. Bark louse № 2 of Fig. 2 (collection number PED

groups within Psocodea are even entirely wingless (e.g. Liposcelidae, "Phthiraptera" (true lice)). Also wing anlagen grow throughout the moults of the immature stages, so that early stages have significantly smaller (barely recognizable or even no discernible) wing anlagen whereas older stages can have, dependant on the adult wing state (brachypterous or macropterous), smaller or larger wing anlagen, though in each case (supposedly) clearly discernible (compare with Badon-
0142). c. Bark louse № 3 of Fig. 3 (collection number BUB 3344). d. Bark louse № 4 of Fig. 4 (collection number BUB 3344)

nel 1938; Kimmins 1941; Sommerman 1943; Finlayson 1949; Broadhead 1961; New 1969, 1979; Dunham 1972; Smithers 1972, 1990, 1995a, b; Mockford 1974, 1977, 1979; Turner 1974b; Hall and Butler 2002).

(4) A further indicator for immature instars appears to be the presence or more specifically the developmental stage (as opposed to the adult stage) of genital structures. Genital structures in bark lice are only suppos- 
edly being present and/or discernible in the last immature instar (Smithers 1972).

(5) Additionally the immatures of some groups of bark lice (some species within Psocidae, Myopsocidae, Amphientomidae, Troctopsocidae; Mockford 1974; Betz 1983; Thornton 1985; Henderson and Hackett 1986; Lienhard 1988; Baz 2008; Lienhard and Baz 2011) exhibit a camouflaging behaviour with specialized hairs (compare also Fig. 8a, d), which seems to be lost in adults. This has been attributed to the presence of wings in adults as debris carried atop the bark louse would hinder flight. If this is the case, we assume that this camouflaging behaviour may also potentially be present in apterous (or brachypterous) bark lice, though there are no such finds in the literature. So the presence of camouflage behaviour of the herein described specimens could be another indicator for immatures.

The first bark louse described herein (Bark louse № 1; BUB 3177; Figs. 1, 9a) is the largest of them (compare also Fig. 9). It carries debris atop its (posterior) thorax and abdomen as a potentially camouflaging behaviour. The carried debris carried obscures the dorsal view, so that it is difficult to ascertain whether the bark louse has wing anlagen or not, and if they are present, in which size (as an indicator of the instar). The posterior end of its abdomen shows a peculiar structure, which could be interpreted as potentially the subgenital plate as genitalia associated structures, though probably not fully developed.

Bark louse № 2 (PED 0142; Figs. 2, 9b) has no discernible wing anlagen present as that area is concealed by debris. Its last abdomen sternite shows peculiar structures, potentially indicating a developing subgenital plate as part of the genital structures. It also carries debris atop its (posterior) thorax and abdomen. This specimen is enclosed together with putative remains of a winged Psocodea, which could be an adult representative of the same species (see discussion above). This would further indicate, that bark louse № 2 represents an immature, but this cannot be further corroborated.

Bark louse № 3 (BUB 3344; Figs. 3, 9c) is the smallest one; it has no wing anlagen discernible. Its last abdomen sternite appears subdivided into two lobes, though not thoroughly, suggesting that the structure is not completely developed yet. It also carries debris atop its thorax and abdomen, though less so than the other specimens.

Bark louse № 4 (BUB 3344; Figs. 4, 9d) is the most difficult to assess as it not only carries debris atop its thorax and abdomen, thus obscuring potentially present wing anlagen, but is also anteriorly within a reflective structure of the amber piece. The dorsal side of the thorax is not assessable and ventrally there appears to be no indication of a wing anlage, so there probably is at least no large wing anlage present. It is possible that there are smaller wing anlagen present, though. The posterior end of its abdomen shows a peculiar, protruding structure, which is reminiscent in its shape of the phallosome as part of the male genitalia (Fig. 4a3). Though the phallosome of extant bark lice is more structured, i.e. consists of cuticular ridges, so that only the overall shape is similar to the phallosome. This may either indicate that the structure is not yet fully developed or that it is not clearly discernible within due to embedding artefacts.

So overall the described bark lice herein are probably immatures, especially bark louse № 1 (Fig. 1) and 2 (Fig. 2). Bark lice № 3 and 4 (Figs. 3, 4) could represent probably later instars, as they have posterior abdomen structures that more clearly resemble adult genital structures, or even adult (especially bark louse № 4; Fig. 4). Though if this is true, the lack of wing anlagen may indicate that at least the ones that are potentially later instars or adults, may be representatives of an apterous or brachypterous species. Additionally if the camouflaging behaviour is truly an immature characteristic, the bark lice described herein would all represent immatures.

\section{Camouflage and debris carrying in insects}

The behaviour of carrying or decorating the body with foreign material (debris) is known in a few in-groups of Insecta, such as in some immatures of the bug group Reduviidae (Hemiptera), lacewing larvae (e.g. aphid lions, Chrysopidae; split-footed lacewings, Nymphidae), caddisfly larvae (Trichoptera) and bark lice (see below). The categorisation of animals decorating themselves as part of camouflage is not unequivocally clear, as this behaviour represents an exceptional case. Here, decorating can function as camouflage, but can also have further functions (Stevens and Ruxton 2019), such as a kind of armour. Decoration as a special form of camouflage does not completely match with the categorisations postulated by Endler (1981) or Stevens and Merilaita (2009) in every case, but can include elements of background matching, disruption and masquerade (Stevens and Ruxton 2019). Yet, in the literature, decoration behaviour has also been termed 'masking'-behaviour (Brandt and Mahsberg 2002; Ramírez et al. 2013). Thus, due to the different levels of perspectives in the terminology concepts of camouflage, each case needs to be investigated in its specific context.

A peculiarity of decorating behaviour is that the debris carried atop the bark lice is what (potentially) camouflages these organisms against their background and not morphologically structures. Though there are potentially morphological structures present here to hold the debris carried atop, as there are in extant bark lice immatures that exhibit the same debris-carrying habit. In these extant forms there are glandular hair (Mockford 1974; Betz 1983; Thornton 
1985; Henderson and Hackett 1986; Lienhard 1988; Baz 2008) or "corkscrew"-shaped hair (Lienhard and Baz 2011) present that help adhere the material carried. No such potential structure could be observed herein, potentially due to the debris covering the specimens, obscuring any such potential structures.

In lacewing larvae the material carried atop the insects not only makes them visually inconspicuous against the background, but also olfactorily. Many lacewing larvae are ambush or sit-and-wait predators, so that camouflage may aid in capturing prey as the prey may only recognize the larvae as an organism and predator too late (crypsis, aggressive mimicry). At the same time the material camouflages it against the background and decreases being detected by predators themselves. A variety of different material carried atop lacewing larvae is known: it ranges from soil and sand as inorganic material to woody material, gastropod shells, lichen or arthropod remains/exuviae (Tauber et al. 2014).

Immatures of the bug group Reduviidae cover themselves with mostly dust and soil, some in-groups have additional material atop which has been termed 'backpack' (Brandt and Mahsberg 2002). This 'backpack' consists of prey remains that were sucked dry and are piled atop its back. These two components seem to have slightly different functions: the dust-coating makes these immatures inconspicuous against the background and the 'backpack', in those groups that have it, masks the shape of the individual, as these backpacks can be quite voluminous and bulky, which both help the individual to avoid detection and prey recognition by predators (masquerade, aggressive mimicry). There are some of these bugs that live with termites and prey on them, and their 'backpack' consists of mostly termite remains that helps them being olfactorily masked and staying undetected by their prey termites.

\section{Debris carrying and camouflage: bark lice described herein}

On all the herein described specimens there is material found exclusively dorsally on the thorax and the abdomen (Fig. 9 for comparison of all specimens). In the two largest ones (Figs. 1, 2, 9a, b) the material consists of densely packed fine sand granules and (probably) also cuticular remains (bark louse № 2 (Figs. 2, 9b) has a putative antenna inside the material carried on its back). In the second smallest one (Figs. 4, 9d), the material atop the specimen appears less dense, dorsal abdominal structures, i.e. tergites, are slightly discernible in between the material. The smallest specimen (Figs. 3, 9c) has more sparsely distributed material atop its thorax and abdomen, so that structures of thorax and abdomen are better discernible here.

This has probably to do with the size of the animals, as the largest animal has (potential) the most material atop its back and the smallest has the least. Though in the two animals, that are of medium and similar size, the slightly larger one has decidedly more material atop its back than the smaller one. It can be argued that these differences are attributed to the embedding process and potential subsequent lose of carried material, though this seems unlikely, as there is no material similar to that on their back around the specimens (Figs. 3, 4, 9c, d). Though the second largest specimen appears to be losing some material posteriorly (Figs. 2, 9b). But in any case it cannot be excluded.

The material atop the specimens has to be either passively accumulated (Betz 1983) or actively deposited onto its dorsal side. So another possibility is that the amount of debris carried atop the specimens is dependent on time, i.e. the more material is atop a specimen the longer it has been in this stage or the closer it is to the consecutive moult, assuming with each moult this material is 'lost' and not reused.

\section{Debris carrying and camouflage in extant bark lice}

All the bark lice described herein carry material (more or less) on their backs (Fig. 9 for overview). This behaviour seems to fit what has been above been described as masking or decorating.

Bark lice in contrast to bug immatures and lacewing larvae are not generally known to prey on other insects or animals. They feed mostly on epiphytes like green algae, fungi and lichens and generally not other animals (e.g. Turner 1984; New 1987), though some may be casual predators (New 1987), as there are bark lice known to feed on coleopteran eggs (Williams 1972) or scale insects (Hemiptera) (Pearman 1932). The debris-carrying behaviour that the bark lice described herein exhibit, may be similarly to concealment strategies within the immature stages of some lacewing and true bugs used to camouflage against the background. Yet, in contrast to the other two which apply aggressive mimicry, they use camouflage likely to be not detected by predators.

As the bark lice described herein all carry fine sand granules, it may be likely that the bark lice were mostly on the ground or potentially on the bark where the camouflaging effect of the carried material appears to most effective. Extant bark-dwelling bark lice are often camouflaged hinting that the specimens described herein may have been bark dwelling and not on the ground. Some of the sand granules appear rounded, indicating that they may have lived near a body of water, potentially a river. So it is also possible that they were ground dwelling, at least for a portion of time. However it appears highly unlikely that they inhabited the leaves of trees, as the debris carried probably would not have provided sufficient camouflage against those. Also there is not a broad pulvillus (mostly lobular, but variable, paired protrusion from the most distal tarsus element) between 
the claws at the tip of the walking appendages in the fossil specimen, which would be a characteristic of extant foliagefrequenting bark lice. There also seem to be fewer foliagefrequenting than bark-dwelling bark lice in the modern fauna (New 1987).

The debris-carrying behaviour has been observed in extant immatures of the groups Psocidae, Myopsocidae (both Psocomorpha), Amphientomidae and Troctopsocidae; in these the material carried atop the individuals is adhered by glandular hairs (Mockford 1974, 1979, 1993; Betz 1983; Thornton 1985; Henderson and Hackett 1986; Lienhard 1988; Smithers 1995b) or potentially by "corkscrew hairs" (Lienhard and Baz 2011). It is thus also possible that such hairs or other structures that help adhere the material to the bark lice are also present in the bark lice described herein. Yet, no indication other than the seemingly adhering material to the specimens has been observed herein.

The winged adults of some bark lice also seem to be camouflaged, though they do not carry debris. The wings of those bark lice show a particular colour pattern that helps them being camouflaged against the background, mostly on bark. Some apterous, bark-frequenting bark lice even seem to have abdominal projections that potentially give them the appearance of thorns or swellings below leaf scars, also camouflaging them against the bark they inhabit (Mockford 1965d in New 1987; Thornton 1985). The eggs of bark-frequenting bark lice also appear to be camouflaged with faeces or casual debris (Betz 1983; New 1987).

\section{Further syninclusions and potential interactions}

There are other inclusions in the same amber piece as the bark lice described herein, identifiable as representatives of Euarthropoda. This may be a tentative indicator of possible interactions between the bark lice and some of the other inclusions found herein or at least hint at the presence of potential predators of bark lice in the ecosystem of the Myanmar Amber.

There are possible mites (Acari; Fig. 5c) and a putative harvestman (Opiliones; Fig. 5b) in close spatial proximity, nearly touching bark louse № 3 in the case of the putative harvestman (Figs. 3a1, a2, b, 5b). Modern day predatory mites are known to prey on bark lice. Together with the close spatial association this makes it possible that there was interaction between the specimens in the amber piece and that the mites and the harvest man where predators of bark lice, but there is no clear indication for that.

There is also a beetle larva (Coleoptera) in close spatial proximity to bark louse № 4 described herein (Figs. 4b1, 5 a) that could potential represent a predator of bark lice. There are cases of beetles (both adult and larval) that prey on bark lice (Turner 1984; Thornton 1985). Though examples of extant beetles preying on bark lice are most prominently ladybugs (Coccinellidae) and the bark lice being preyed upon mimic them to avoid detection (Mockford 1974 in New 1987). The bark lice and also the beetle larva described herein do not resemble ladybugs. On the other hand there are also bark lice preying on beetle eggs, though there is no indication that this is the case here, either.

There is also a potentially parasitoid wasp (Chrysidoidea; Fig. 6a) as a syninclusion of bark louse № 2 (Fig. 2), but in no close spatial proximity. Still it has to be mentioned that wasps of the groups Braconidae and Mymaridae (Sommerman 1956; Turner 1974a; Broadhead and Cheke 1975; Thornton 1985; New 1987: table 5) are parasitoids of extant bark lice (mostly eggs, but also immatures). Though the wasp does not appear to belong in either group.

Altogether, it would be at least plausible that there have been interactions between the different species, but it cannot be corroborated for the here presented individuals. Certainly, it can be stated, that these species are coexisting in the same habitat closely.

\section{Conclusion}

Decorating or masking behaviour in context of camouflage is known for immature of some groups within Psocodea, but the evolution of this strategy is mainly unknown so far. Fossil evidences for camouflaging behaviour is extremely rare and only some cases were described in the literature (Kácha et al. 1995; Boucot and Poinar 2010; Pérez-de la Fuente et al. 2012; Wang et al. 2016).

The four specimens described herein, represent one of the first fossil evidences of decorating behaviour in Psocodea, indicating that this strategy was already present in the Cretaceous 100 million years ago. The specimens are likely representatives of different groups within Psocodea, at least different species, so this strategy could be more widespread within Cretaceous bark lice. As there is no indication of bark lice as predators, it seems most likely that this represents a defensive strategy to avoid being captured by predators. The decorating behaviour could result in hampered recognition of the bark lice by predators, but also additional physical armour. This allows also the conclusion that these representatives of Psocodea were under predatory pressure. As putative predators there are several possible groups known in Myanmar amber, some also preserved as syninclusions of the here preserved specimens, but whether these groups indeed predated on bark lice in the Cretaceous amber forest remains still unclear.

To reconstruct a possible scenario of the evolution of the camouflaging strategy within the groups of Psocodea and also to pursue the question whether this strategy possibly evolved several times independently within different groups of Psocodea, further investigations are needed. This 
is especially true for morphology of extant immature of different groups within Psocodea to at least narrow down fossil findings to a certain group, but also for fossil representatives. The here described specimens represent likely immature stages. In this case, this would be indeed the first description of non-true lice psocodean immatures, or, if they represent adults, the first apterous forms in Myanmar amber. Even if the identification to a specific group is currently not possible, this is an important contribution to the fragmentary knowledge of the faunal composition of the Cretaceous amber forest, and in the evolution of strategies for avoiding predation and food-webs.

Acknowledgements CK is kindly funded by the Landesgraduiertenförderung MV. The Volkswagen Foundation kindly funds JTH with a Lichtenberg Professorship. CK, JTH and MKH thank J. M. Starck, Munich, and S. Harzsch, Greifswald, for their continuous support. We furthermore thank C. Haug, Munich, J. Krieger, Greifswald, and C. Heuft, Munich, for their support and helpful discussions. We would also like to thank M. Husemann, Hamburg, for help and access to the Entomology collection of the Centrum für Naturkunde, University of Hamburg. U. Wimmer, Munich, is thanked for her help with imaging and subsequent processing. We would also like to thank D. Azar and an anonymous reviewer for their helpful comments that helped improve the manuscript. We highly appreciate the effort of all people involved in providing open access, open source and low cost software.

Funding Open Access funding enabled and organized by Projekt DEAL

Open Access This article is licensed under a Creative Commons Attribution 4.0 International License, which permits use, sharing, adaptation, distribution and reproduction in any medium or format, as long as you give appropriate credit to the original author(s) and the source, provide a link to the Creative Commons licence, and indicate if changes were made. The images or other third party material in this article are included in the article's Creative Commons licence, unless indicated otherwise in a credit line to the material. If material is not included in the article's Creative Commons licence and your intended use is not permitted by statutory regulation or exceeds the permitted use, you will need to obtain permission directly from the copyright holder. To view a copy of this licence, visit http://creativecommons.org/licenses/by/4.0/.

\section{References}

Ahmedani, M.S., N. Shagufta, M. Aslam, and S.A. Hussnain. 2010. Psocid: A new risk for global food security and safety. Applied Entomology and Zoology 45(1): 89-100. https://doi.org/10.1303/ aez.2010.89.

Aldrich, J.R., and Q.H. Zhang. 2016. Chemical ecology of Neuroptera. Annual Review of Entomology 61: 197-218. https://doi.org/10. 1146/annurev-ento-010715-023507.

Athanassiou, C.G., F.H. Arthur, and J.E. Throne. 2010. Efficacy of methoprene for control of five species of psocids (Psocoptera) on wheat, rice, and maize. Journal of Food Protection 73(12): 2244-2249. https://doi.org/10.4315/0362-028X-73.12.2244.

Ax, P. 2000. Multicellular Animals: The Phylogenetic System of the Metazoa, Vol. 2, 1-396. Berlin/Heidelberg: Springer. https://doi. org/10.1007/978-3-662-10396-8.
Azar, D. 2000. L'ambre Mésozoïque du Liban. Unpublished PhD Thesis. Orsay, University of Paris XI.

Azar, D., and M.S. Engel. 2008. A sphaeropsocid bark louse in Late Cretaceous amber from Siberia (Psocoptera: Sphaeropsocidae). Transactions of the Kansas Academy of Science 111(1/2): 141146. https://doi.org/10.1660/0022-8443(2008)111[141:asblil] 2.0.co;2.

Azar, D., and A. Nel. 2004. Four new Psocoptera from Lebanese amber (Insecta: Psocomorpha: Trogiomorpha). Annales de la Société Entomologique de France 40(2): 185-192. https://doi.org/10. 1080/00379271.2004.10697415.

Azar, D., and A. Nel. 2011. The oldest psyllipsocid booklice, in Lower Cretaceous amber from Lebanon (Psocodea, Trogiomorpha, Psocathropetae, Psyllipsocidae). ZooKeys 130: 153-165. https://doi. org/10.3897/zookeys.130.1430.

Azar, D., L. Hajar, C. Indary, and A. Nel. 2008. Paramesopsocidae, a new Mesozoic psocid family (Insecta: Psocodea "Psocoptera": Psocomorpha). Annales de la Société Entomologique de France 44(4): 459-470. https://doi.org/10.1080/00379271.2008.10697 581.

Azar, D., A. Nel, and D. Néraudeau. 2009. A new Cretaceous psocodean family from the Charente-Maritime amber (France) (Insecta, Psocodea, Psocomorpha). Geodiversitas 31(1): 117127. https://doi.org/10.5252/g2009n1a10.

Azar, D., M.S. Engel, and D.A. Grimaldi. 2010a. A new genus of sphaeropsocid bark lice from the Early Cretaceous amber of Lebanon (Psocodea: Sphaeropsocidae). Annales de la Société Entomologique de France 46(1-2): 103-107. https://doi.org/10. 1080/00379271.2010.10697643.

Azar, D., A. Nel, and J.F. Petrulevičius. 2010b. First psocodean (Psocodea, Empheriidae) from the Cretaceous amber of New Jersey. Acta Geologica Sinica (English Edition) 84(4): 762-767. https:// doi.org/10.1111/j.1755-6724.2010.00255.x.

Azar, D., A. Nel, and V. Perrichot. 2015. Diverse barklice (Psocodea) from Late Cretaceous Vendean amber. Paleontological Contributions 2014(10C): 9-15. https://doi.org/10.17161/PC.1808.15983.

Badonnel, A. 1938. Sur la biologie de Psyllipsocus ramburii SélysLongchamps [Psocoptera]. Bulletin de la Société Entomologique de France 43(11-12): 153-158.

Baz, A. 2008. Bark-lice, book-lice or psocids (Psocoptera). In Encyclopedia of Entomology, ed. J.L. Capinera, 381-399. Dordrecht: Kluwer. https://doi.org/10.1007/0-306-48380-7_416.

Baz, A., and V.M. Ortuño. 2000. Archaeatropidae, a new family of Psocoptera from the Cretaceous amber of Alava, Northern Spain. Annals of the Entomological Society of America 93(3): 367-373. https://doi.org/10.1603/0013-8746(2000)093[0367:AANFOP] 2.0.CO;2.

Baz, A., and V.M. Ortuño. 2001a. New genera and species of empheriids (Psocoptera: Empheriidae) from the Cretaceous amber of Alava, northern Spain. Cretaceous Research 22: 575-584. https://doi.org/10.1006/cres.2001.0275.

Baz, A., and V.M. Ortuño. 2001b. A new electrentomoid psocid (Psocoptera) from the Cretaceous amber of Alava (Northern Spain). Mitteilungen aus dem Museum für Naturkunde in Berlin. Deutsche Entomologische Zeitschrift 48(1): 27-32. https://doi. org/10.1002/mmnd.4800480104.

Betz, B.W. 1983. The biology of Trichadenotecnum alexanderae Sommerman (Psocoptera: Psocidae). III. Analysis of mating behavior. Psyche 90(1-2): 97-117. https://doi.org/10.1155/1983/97420.

Boucot, A.J., and G.O. Poinar Jr. 2010. Fossil behavior compendium, 1-363. Boca Raton, Fla.: CRC Press.

Brandt, M., and D. Mahsberg. 2002. Bugs with a backpack: The function of nymphal camouflage in the West African assassin bugs Paredocla and Acanthaspis spp. Animal Behaviour 63: 277-284. https://doi.org/10.1006/anbe.2001.1910. 
Broadhead, E. 1961. The biology of Psoquilla marginepunctata (Hagen) (Corrodentia, Trogiidae). Transactions of the Society for British Entomology 14(10): 223-236.

Broadhead, E., and R.A. Cheke. 1975. Host spatial pattern, parasitoid interference and the modelling of the dynamics of Alaptus fusculus (Hym.: Mymaridae), a parasitoid of two mesopsocus species (Psocoptera). Journal of Animal Ecology 44(3): 767-793. https:// doi.org/10.2307/3718.

Carpenter, F.M. 1932. The Lower Permian insects of Kansas. Part 5. Psocoptera and additions to the Homoptera. American Journal of Science 24(139): 1-22. https://doi.org/10.2475/ajs.s5-24.139.1.

Carpenter, F.M. 1933. The Lower Permian insects of Kansas. Part 6. Delopteridae, Protelytroptera, Plectoptera and a new collection of Protodonata, Odonata, Megasecoptera, Homoptera, and Psocoptera. Proceedings of the American Academy of Arts and Science 68(11): 411-504. https://doi.org/10.2307/20022959.

Carpenter, F.M. 1939. The Lower Permian insects of Kansas. Part 8: additional Megasecoptera, Protodonata, Odonata, Homoptera, Psocoptera, Protelytroptera, Plectoptera, and Protoperlaria. Proceedings of the American Academy of Arts and Science 73(3): 29-70. https://doi.org/10.2307/25130151.

Choufani, J., D. Azar, and A. Nel. 2011. The oldest amphientomete booklouce from Lower Cretaceous amber of Lebanon (Psocodea: Troctomorpha). Insect Systematics and Evolution 42: 149-159. https://doi.org/10.1163/187631211X579405.

Cloudsley-Thompson, J.L. 1981. Comments on the nature of deception. Biological Journal of the Linnean Society 16(1): 11-14. https:// doi.org/10.1111/j.1095-8312.1981.tb01837.x.

Cott, H.B. 1940. Adaptive Coloration in Animals, 1-557. London: Methuen \& Co., Ltd.

Cuadrado, M., J. Martiân, and P. Loâpez. 2001. Camouflage and escape decisions in the common chameleon Chamaeleo chamaeleon. Biological Journal of the Linnean Society 72(4): 547-554. https://doi.org/10.1006/bij1.2000.0515.

Cuthill, I.C., and T.S. Troscianko. 2009. Animal camouflage: Biology meets psychology, computer science and art. International Journal of Design and Nature and Ecodynamics 4(3): 183202. https://doi.org/10.2495/DNE-V4-N3-183-202.

Dettner, K., and C. Liepert. 1994. Chemical mimicry and camouflage. Annual Review of Entomology 39: 129-154. https://doi. org/10.1146/annurev.en.39.010194.001021.

Dunham, R.S. 1972. A life history study of Caecilius aurantiacus (Hagen) (Psocoptera: Caeciliidae). The Great Lakes Entomologist 5(1): 17-27.

Durden, L.A. 2019. Lice (Phthiraptera). In Medical and Veterinary Entomology, 3rd ed., eds. G.R. Mullen and L.A. Durden, 79-106. London etc.: Academic Press. https://doi.org/10.1016/ b978-0-12-814043-7.00007-8.

Edmunds, M. 1981. On defining 'mimicry.' Biological Journal of the Linnean Society 16(1): 9-10. https://doi.org/10.1111/j.10958312.1981.tb01836.x.

Enderlein, G. 1924. Über die Drüsenhaare der Larven und Nymphen einiger Gattungen von Copeognathen (Beiträge zur Kenntniss der Copeognathen VIII). Tijdschrift voor Entomologie 67: $72-74$.

Endler, J.A. 1978. A Predator's View of Animal Color Patterns. In Evolutionary Biology, vol. 11, eds. M.K. Hecht, W.C. Steere, and B. Wallace, 319-364. New York: Springer. https://doi.org/ 10.1007/978-1-4615-6956-5_5.

Endler, J.A. 1981. An overview of the relationships between mimicry and crypsis. Biological Journal of the Linnean Society 16(1): 25-31. https://doi.org/10.1111/j.1095-8312.1981.tb01840.x.

Finlayson, L.H. 1949. The life-history and anatomy of Lepinotus patruelis Pearman (Psocoptera - Atropidae). Proceedings of the Zoological Society of London 119(2): 301-323. https://doi.org/ 10.1111/j.1096-3642.1949.tb00881.x.
Gao, T., X. Yin, C. Shih, A.P. Rasnitsyn, X. Xu, S. Chen, C. Wang, and D. Ren. 2019. New insects feeding on dinosaur feathers in MidCretaceous amber. Nature Communications 10: 5424. https://doi. org/10.1038/s41467-019-13516-4.

Gelhaus, J.K., and R. Johnson. 1996. First record of crane flies (Tipulidae: Limoniinae) in Upper Cretaceous amber from New Jersey, U.S.A. Transactions of the American Entomological Society 122(1): 55-65. www.jstor.org/stable/25078603. Accessed 3 March 2021.

Grimaldi, D.A., and M.S. Engel. 2005. Evolution of the Insects, 1-755. New York, N.Y.: Cambridge University Press. https://doi.org/10. 1017/S001675680700372X.

Grimaldi, D.A., and M.S. Engel. 2006a. Fossil Liposcelididae and the lice ages (Insecta: Psocodea). Proceedings of the Royal Society of London (B: Biological Sciences) 273(1586): 625-633. https:// doi.org/10.1098/rspb.2005.3337.

Grimaldi, D., and M.S. Engel. 2006b. Extralimital fossils of the "Gondwanan" family Sphaeropsocidae (Insecta: Psocodea). American Museum Novitates 2006(3523): 1-18. https://doi.org/10.1206/ 0003-0082(2006)3523[1:EFOTGF]2.0.CO;2.

Hall, D.W., and J.F. Butler. 2002. A Webbing Barklouse, a psocid, Archipsocus nomas Gurney (Insecta: Psocoptera: Archipsocidae): 1-2. This document is EENY-275, one of a series of Featured Creatures from the University of Florida's Entomology and Nematology Department and the Florida Department of Agriculture and Consumer Services' Division of Plant Industry. http:// entnemdept.ufl.edu/creatures/trees/barklouse.htm (website) and http://citeseerx.ist.psu.edu/viewdoc/download?doi=10.1.1.738. 9638\&rep=rep1\&type $=$ pdf (pdf-file). Accessed 3 March 2021.

Hanlon, R.T. 2007. Cephalopod dynamic camouflage. Current Biology 17(11): R400-R404. https://doi.org/10.1016/j.cub.2007.03.034.

Haug, J.T. 2019. Categories of developmental biology: Examples of ambiguities and how to deal with them. In Perspectives on Evolutionary and Developmental Biology. Essays for Alessandro Minelli. Festschrift 2, ed. G. Fusco, 93-102. Padova: Padova University Press.

Haug, J.T. 2020. Why the term "larva" is ambiguous, or what makes a larva? Acta Zoologica 101(2): 167-188. https://doi.org/10.1111/ azo. 12283

Haug, C., G. Mayer, V. Kutschera, D. Waloszek, A. Maas, and J.T. Haug. 2011. Imaging and documenting gammarideans. International Journal of Zoology 2011: 380829. https://doi.org/10. 1155/2011/380829.

Henderson, A., and D.J. Hackett. 1986. Lichen and algal camouflage and dispersal in the psocid nymph Trichadenotecnum fasciatum. The Lichenologist 18(2): 199-200. https://doi.org/10.1017/S0024 282986000257.

Hicks, E.A. 1959. Check-List and Bibliography on the Occurrence of Insects in Birds' Nests, 1-681. Ames, Io.: The Iowa State College Press. https://doi.org/10.2307/4510797.

Hörnig, M.K., C. Haug, J. Schneider, and J.T. Haug. 2018. Evolution of reproductive strategies in dictyopteran insects-clues from ovipositor morphology of extinct roachoids. Acta Palaeontologica Polonica 63(1): 1-24. https://doi.org/10.4202/app.00324.2016.

Howard, R.W., R.D. Akre, and W.B. Garnett. 1990. Chemical mimicry in an obligate predator of carpenter ants (Hymenoptera: Formicidae). Annals of the Entomological Society of America 83(3): 607-616. https://doi.org/10.1093/aesa/83.3.607.

Johnson, K.P., and E.L. Mockford. 2003. Molecular systematics of Psocomorpha (Psocoptera). Systematic Entomology 28(3): 409-416. https://doi.org/10.1046/j.1365-3113.2003.00220.x.

Johnson, K.P., K. Yoshizawa, and V.S. Smith. 2004. Multiple origins of parasitism in lice. Proceedings of the Royal Society of London (B: Biological Sciences) 271(1550): 1771-1776. https://doi.org/ 10.1098/rspb.2004.2798. 
Johnson, K.P., C.H. Dietrich, F. Friedrich, R.G. Beutel, B. Wipfler, R.S. Peters, J.M. Allen, M. Petersen, A. Donath, K.K.O. Walden, A.M. Kozlov, L. Podsiadlowski, C. Mayer, K. Meusemann, A. Vasilikopoulos, R.M. Waterhouse, S.L. Cameron, C. Weirauch, D.R. Swanson, D.M. Percy, N.B. Hardy, I. Terry, S. Liu, X. Zhou, B. Misof, H.M. Robertson, and K. Yoshizawa. 2018. Phylogenomics and the evolution of hemipteroid insects. Proceedings of the National Academy of Sciences of the United States of America 115(50): 12775-12780. https://doi.org/10.1073/pnas. 1815820115.

Kácha, P., and V. Petr. 1995. Camouflage and mimicry in fossils,

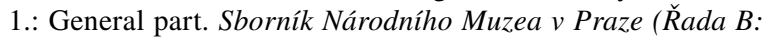
Přirodni Vědy) [=Acta Musei Nationalis Pragae (B: Historia Naturalis)] 51(1-4): 53-82.

Kim, K.C., and H.W. Ludwig. 1978. Phylogenetic relationships of parasitic Psocodea and taxonomic position of the Anoplura. Annals of the Entomological Society of America 71(6): 910-922. https:// doi.org/10.1093/aesa/71.6.910.

Kimmins, D.E. 1941. XXXIV. Notes on British Psocoptera. I. Elipsocus hyalinus (Steph.), and its allies. Annals and Magazine of Natural History (Series 11) 7(42): 520-530. https://doi.org/10. 1080/03745481.1941.9723715.

Knight, O.L.M. 1950. Fossil insect beds of Belmont, NSW. Records of the Australian Museum 22(3): 251-253. https://doi.org/10.3853/j. 0067-1975.22.1950.606.

Kučerová, Z. 1997. Macropterous form of Dorypteryx domestica (Psocoptera: Psyllipsocidae). European Journal of Entomology 94(4): 567-573.

Kučerová, Z. 1998. Wing polymorphism in Dorypteryx domestica (Smithers) (Psocoptera: Psyllipsocidae). Insect Systematics and Evolution 29(4): 451-457. https://doi.org/10.1163/18763 $1298 \times 00069$.

Kučerová, Z. 2002. Stored product psocids (Psocoptera): External morphology of eggs. European Journal of Entomology 99(4): 491-503. https://doi.org/10.14411/eje.2002.066.

Kučerová, Z. 2007. Nymph's morphology of Dorypteryx domestica (Psocoptera). Integrated Protection of Stored Products IOBC/ WPRS Bulletin 30: 161-165.

Kučerová, Z., Z. Li, and J. Hromádková. 2009. Morphology of nymphs of common stored-product psocids (Psocoptera, Liposcelididae). Journal of Stored Products Research 45(1): 54-60. https://doi.org/10.1016/j.jspr.2008.08.002.

Lienhard, C. 1988. Three new extra-neotropical species of Troctopsocidae (Insecta: Psocoptera). Journal of Natural History 22(3): 575-587. https://doi.org/10.1080/00222938800770391.

Lienhard, C., and A. Baz. 2011. Redescription of the genus Marcenendius Navás (Psocodea: Psocoptera: Amphientomidae) with a key to western Palaearctic amphientomids. Revue Suisse de Zoologie 118(3): 451-466.

Lyal, C.H.C. 1985. Phylogeny and classification of the Psocodea, with particular reference to the lice (Psocodea: Phthiraptera). Systematic Entomology 10(2): 145-165. https://doi.org/10. 1111/j.1365-3113.1985.tb00525.x.

Meijer-Kuiper, W. 1993. Skin patterning in Octopus vulgaris and its importance for camouflage. Unpublished Master's Thesis, 1-42. Groningen: University of Groningen.

Mitzutani, A., J.S. Chahl, and M.V. Srinivasan. 2003. Motion camouflage in dragonflies. Nature 423(6940): 604. https://doi.org/ $10.1038 / 423604 a$.

Mockford, E.L. 1967. The electrentomoid psocids (Psocoptera). Psyche A Journal of Entomology 74: 118-165. https://doi.org/10. $1155 / 1967 / 862560$.

Mockford, E.L. 1974. Trichadenotecnum circularoides (Psocoptera: Psocidae) in Southeastern United States, with notes on its reproduction and immature stages. The Florida Entomologist 57(4): 369-370.
Mockford, E.L. 1977. Asiopsocus sonorensis (Psocoptera: Asiopsocidae): A new record, augmented description, and notes on reproductive biology. The Southwestern Naturalist 22(1): 21-29. https://doi.org/10.2307/3670461.

Mockford, E.L. 1979. Diagnoses, distribution, and comparative life history notes on Aaroniella maculosa (Aaron) and A. eertmoedi N.SP. (Psocoptera: Philotarsidae). The Great Lakes Entomologist 12(1): 35-44.

Mockford, E.L. 1993. North American Psocoptera (Insecta). Fauna and Flora Handbook no. 10, 1-480. Boca Raton, Fla.: CRC Press.

Mockford, E.L., C. Lienhard, and K. Yoshizawa. 2013. Revised classification of Psocoptera from Cretaceous amber, a reassessment of published information. Insecta matsumurana. Journal of the Faculty of Agriculture Hokkaido University, Series Entomology 69: 1-26. http://hdl.handle.net/2115/53635. Accessed 3 March 2021.

Murrell, A., and S.C. Barker. 2005. Multiple origins of parasitism in lice: Phylogenetic analysis of SSU rDNA indicates that the Phthiraptera and Psocoptera are not monophyletic. Parasitology Research 97: 274-280. https://doi.org/10.1007/ s00436-005-1413-8.

Nel, A., A. Roques, P. Nel, A.A. Prokin, T. Bourgoin, J. Prokop, J. Swedo, D. Azar, L. Desutter-Grandcolas, T. Wappler, R. Garrouste, D. Coty, D. Huang, M.S. Engel, and A.G. Kirejtshuk. 2013. The earliest known holometabolous insects. Nature 503(7475): 257-261. https://doi.org/10.1038/nature12629.

New, T.R. 1969. The early stages and life histories of some British foliage-frequenting Psocoptera, with notes on the overwintering stages of British arboreal Psocoptera. Transactions of the Royal Entomological Society of London 121(3): 59-77. https:// doi.org/10.1111/j.1365-2311.1969.tb00517.x.

New, T.R. 1979. The early stages of Ptenopsila Enderlein (Psocoptera, Caeciliidae). Studies on Neotropical Fauna and Environment 14(2-3): 171-176. https://doi.org/10.1080/01650527909360553.

New, T.R. 1987. Biology of the Psocoptera. Oriental Insects 21(1): 1-109. https://doi.org/10.1080/00305316.1987.11835472.

Pearman, J.V. 1932. Some coccophagous psocids (Psocoptera) from East Africa. Proceedings of the Royal Entomological Society of London (B: Taxonomy) 1(4): 90-96. https://doi.org/10.1111/j. 1365-3113.1932.tb01360.x.

Pérez-de la Fuente, R., X. Delclòs, E. Peñalver, M. Speranza, J. Wierzchos, C. Ascaso, and M.S. Engel. 2012. Early evolution and ecology of camouflage in insects. Proceedings of the National Academy of Sciences of the United States of America 109(52): 21414-21419. https://doi.org/10.1073/pnas.1213775110.

Perrichot, V. 2004. Early Cretaceous amber from south-western France: Insight into the Mesozoic litter fauna. Geologica Acta 2(1): 9-22. https://doi.org/10.1344/105.000001629.

Perrichot, V., D. Azar, D. Néraudeau, and A. Nel. 2003. New Psocoptera in the Early Cretaceous amber of SW France and Lebanon (Insecta: Psocoptera: Trogiomorpha). Geological Magazine 140(6): 669-683. https://doi.org/10.1017/S0016756803008355.

Perrichot, V., D. Néraudeau, A. Nel, and G. de Ploëg. 2007. A reassessment of the Cretaceous amber deposits from France and their palaeontological significance. African Invertebrates 48(1): 213-227.

Poinar, G.O., Jr., and R. Milki. 2001. Lebanese Amber. The Oldest Insect Ecosystem in Fossilized Resin, 1-96. Corvallis, Oreg.: Oregon State University Press.

Poulton, E.B. 1898. Natural selection the cause of mimetic resemblance and common warning colours. Zoological Journal of the Linnean Society 26(172): 558-612. https://doi.org/10.1111/j.1096-3642. 1898.tb01734.x.

Ramírez, P.A., A. González, and C. Botto-Mahan. 2013. Masking behavior by Mepraia spinolai (Hemiptera: Reduviidae): Anti-predator defense and life history trade-offs. 
Journal of Insect Behavior 26: 592-602. https://doi.org/10.1007/ s10905-012-9371-3.

Rettenmeyer, C.W. 1970. Insect mimicry. Annual Review of Entomology 15: 43-74. https://doi.org/10.1146/annurev.en.15.010170. 000355.

Robinson, M.H. 1981. A stick is a stick and not worth eating: on the definition of mimicry. Biological Journal of the Linnean Society 16(1): 15-20. https://doi.org/10.1111/j.1095-8312.1981.tb018 38.x.

Roesler, R.-U. 1987. Mimikry und Phylogenie. Atalanta 18: 195-203.

Roesler, R.-U., and P.V. Küppers. 1977. Beiträge zur Kenntnis der Insektenfauna Sumatras Teil 6: Betrachtungen zum Problemkreis "Mimikry" am Beispiel südostasiatischer Insekten. Beiträge zur Naturkundlichen Forschung in Südwestdeutschland 36: 113-151.

Ross, A.J. 2020. Burmese (Myanmar) amber taxa, on-line supplement v.2020.1: 25 pp. http://www.nms.ac.uk/explore/stories/naturalworld/burmese-amber/. Accessed 3 March 2021.

Rothschild, M. 1981. The mimicrats must move with the times. Biological Journal of the Linnean Society 16(1): 21-23. https://doi. org/10.1111/j.1095-8312.1981.tb01839.x.

Ruxton, G.D. 2009. Non-visual crypsis: A review of the empirical evidence for camouflage to senses other than vision. Philosophical Transactions of the Royal Society (B: Biological Sciences) 364(1516): 549-557. https://doi.org/10.1098/rstb.2008.0228.

Ruxton, G.D., and Martin Stevens. 2015. The evolutionary ecology of decorating behaviour. Biology Letters 11(6): 20150325. https:// doi.org/10.1098/rsbl.2015.0325.

Schlüter, T. 1978. Zur Systematik und Palökologie harzkonservierter Arthropoda einer Taphozönose aus dem Cenomanium von NW-Frankreich. Berliner Geowissenschaftliche Abhandlungen (A: Geologie und Paläontologie) 9: 1-150. https://doi.org/10. 23689/fidgeo-3142

Seeger, W. 1975. Funktionsmorphologie an Spezialbildungen der Fühlergeißel von Psocoptera und anderen Paraneoptera (Insecta); Psocodea als monophyletische Gruppe. Zeitschrift für Morphologie der Tiere 81: 137-159. https://doi.org/10.1007/BF00301153

Skelhorn, J., H.M. Rowland, M.P. Speed, and G.D. Ruxton. 2010. Masquerade: Camouflage without crypsis. Science 327(5961): 51. https://doi.org/10.1126/science.1181931.

Smithers, C.N. 1972. The Classification and Phylogeny of the Psocoptera. The Australian Museum Memoir 14:1-351.

Smithers, C.N. 1990. Keys to the families and genera of Psocoptera (Arthropoda: Insecta). Technical Reports of the Australian Museum 2: 1-82. https://doi.org/10.3853/j.1031-8062.2.1990.77.

Smithers, C.N. 1995a. Psilopsocus mimulus Smithers (Psocoptera: Psilopsocidae), the first known wood-boring psocopteran. Australian Journal of Entomology 34(2): 117-120. https://doi.org/ 10.1111/j.1440-6055.1995.tb01299.x.

Smithers, C.N. 1995b. Final instar nymph of Psilopsocus nebulosus Mockford (Psocoptera: Psilopsocidae), redescribed and compared with two wood-boring species of the genus. Beiträge zur Entomologie/Contributions to Entomology 45(2): 375-381. https://doi.org/10.21248/contrib.entomol.45.2.375-381.

Sommerman, K.M. 1943. Description and bionomics of Caecilius manteri n. sp. (Corrodentia). Proceedings of the Entomological Society of Washington 45(2): 29-39.

Sommerman, K.M. 1956. Parasitization of nymphal and adult psocids. Proceedings of the Entomological Society of Washington 58(3): 149-152.

Spahr, U. 1992. Ergänzungen und Berichtigungen zu R. Keilbachs Bibliographie und Liste der Bernsteinfossilien-Klasse Insecta (ausgenommen:" Apterygota", Hemipteroidea, Coleoptera, Hymenoptera, Mecopteroidea). Stuttgarter Beiträge Naturkunde (B: Geologie und Paläontologie) 182: 1-102.
Stevens, M., and S. Merilaita. 2009. Animal camouflage: Current issues and new perspectives. Philosophical Transactions of the Royal S 364(1516): 423-427. https://doi.org/10.1098/rstb.2008.0217.

Stevens, M., and G.D. Ruxton. 2019. The key role of behaviour in animal camouflage. Biological Reviews 94(1): 116-134. https:// doi.org/10.1111/brv.12438.

Stuart-Fox, D., M.J. Whiting, and A. Moussalli. 2006. Camouflage and colour change: Antipredator responses to bird and snake predators across multiple populations in a dwarf chameleon. Biological Journal of the Linnean Society 88(3): 437-446. https://doi. org/10.1111/j.1095-8312.2006.00631.x.

Tauber, C.A., M.J. Tauber, and G.S. Albuquerque. 2014. Debriscarrying in larval Chrysopidae: Unraveling its evolutionary history. Annals of the Entomological Society of America 107(2): 295-314. https://doi.org/10.1603/AN13163.

Thornton, I.W.B. 1985. The geographical and ecological distribution of arboreal Psocoptera. Annual Review of Entomology 30: 175-196. https://doi.org/10.1146/annurev.ento.30.1.175.

Tillyard, R.J. 1926. Kansas Permian insects. Part 8. The order Copeognatha. American Journal of Sciences (Series 5) 11(64): 315-349. https://doi.org/10.2475/ajs.s5-11.64.315.

Turner, B.D. 1974a. The population dynamics of tropical arboreal Psocoptera (Insecta) on two species of conifers in the Blue Mountains, Jamaica. Journal of Animal Ecology 43(2): 323-337. https://doi.org/10.2307/3368.

Turner, B.D. 1974b. The abdominal adhesive organs of Caecilius equivocates Mockford (Caeciliidae, Psocoptera, Insecta). Journal of Natural History 8(4): 427-431. https://doi.org/10.1080/ 00222937400770361.

Turner, B.D. 1984. Predation pressure on the arboreal epiphytic herbivores of larch trees in southern England. Ecological Entomology 9(1): 91-100. https://doi.org/10.1111/j.1365-2311.1984. tb00701.x.

Turner, B.D. 1994. Liposcelis bostrychophila (Psocoptera: Liposcelididae), a stored food pest in the UK. International Journal of Pest Management 40(2): 179-190. https://doi.org/10.1080/09670 879409371879.

Vane-Wright, R.I. 1980. On the definition of mimicry. Biological Journal of the Linnean Society 13(1): 1-6. https://doi.org/10.1111/j. 1095-8312.1980.tb00066.x.

Vishnyakova, V.N. 1975. Psocoptera in Late-Cretaceous insect-bearing resins from the Taimyr. Entomologicheskoe Obozrenie 54(2): $63-75$.

Wang, B., F. Xia, M.S. Engel, V. Perrichot, G. Shi, H. Zhang, J. Chen, E.A. Jarzembowski, T. Wappler, and J. Rust. 2016. Debris-carrying camouflage among diverse lineages of Cretaceous insects. Science Advances 2(6): e1501918. https://doi.org/10.1126/sciadv.1501918.

Wickler, W. 1968. Mimicry in plants and animals, 1-255. London: World Univ. Library.

Wiens, D. 1978. Mimicry in plants. In Evolutionary Biology, vol. 11 , eds. M.K. Hecht, W.C. Steere, and B. Wallace, 365403. New York, N.Y.: Springer. https://doi.org/10.1007/ 978-1-4615-6956-5_6.

Williams, L.H. 1972. Anobiid beetle eggs consumed by a psocid (Psocoptera: Liposcelidae). Annals of the Entomological Society of America 65(3): 533-536. https://doi.org/10.1093/aesa/65.3.533.

Yang, Q., S. Zhao, Z. Kučerová, V. Stejskal, G. Opit, M. Qin, Y. Cao, F. Li, and Z. Li. 2013. Validation of the $16 \mathrm{~S}$ rDNA and COI DNA barcoding technique for rapid molecular identification of stored product psocids (Insecta: Psocodea: Liposcelididae). Journal of Economic Entomology 106(1): 419-425. https://doi.org/10.1603/ EC12163.

Yoshizawa, K. 2002. Phylogeny and higher classification of suborder Psocomorpha (Insecta: Psocodea: 'Psocoptera'). Zoological 
Journal of the Linnean Society 136(3): 371-400. https://doi.org/ 10.1046/j.1096-3642.2002.00036.x.

Yoshizawa, K. 2005. Morphology of Psocomorpha (Psocodea: 'Psocoptera'). Insecta matsumurana. Journal of the Faculty of Agriculture Hokkaido University, Series Entomology 62: 1-44. http:// hdl.handle.net/2115/10524. Accessed 3 March 2021.

Yoshizawa, K., and K.P. Johnson. 2006. Morphology of male genitalia in lice and their relatives and phylogenetic implications. Systematic Entomology 31(2): 350-361. https://doi.org/10.1111/j. 1365-3113.2005.00323.x.

Yoshizawa, K., and C. Lienhard. 2010. In search of the sister group of the true lice: A systematic review of booklice and their relatives, with an updated checklist of Liposcelididae (Insecta: Psocodea). Arthropod Systematics and Phylogeny 68(2): 181-195. http://hdl. handle.net/2115/47518. Accessed 3 March 2021.
Yoshizawa, K., and C. Lienhard. 2020. Cormopsocidae: A new family of the suborder Trogiomorpha (Insecta: Psocodea) from Burmese amber. Entomological Science 23(2): 208-215. https://doi.org/ 10.1111/ens.12414.

Yoshizawa, K., C. Lienhard, and K.P. Johnson. 2006. Molecular systematics of the suborder Trogiomorpha (Insecta: Psocodea: 'Psocoptera'). Zoological Journal of the Linnean Society 146(2): 287-299. https://doi.org/10.1111/j.1096-3642.2006.00207.x.

Zrzavý, J. 2008. Four chapters about the monophyly of insect "orders": A review of recent phylogenetic contributions. Acta Entomologica Musei Nationalis Pragae 48(2): 217-232. 